\title{
WestVirginiaUniversity
}

THE RESEARCH REPOSITORY @ WVU

Graduate Theses, Dissertations, and Problem Reports

1999

\section{Designing a cultural needs questionnaire}

\author{
Sabah Karayegen \\ West Virginia University
}

Follow this and additional works at: https://researchrepository.wvu.edu/etd

\section{Recommended Citation}

Karayegen, Sabah, "Designing a cultural needs questionnaire" (1999). Graduate Theses, Dissertations, and Problem Reports. 765.

https://researchrepository.wvu.edu/etd/765

This Thesis is protected by copyright and/or related rights. It has been brought to you by the The Research Repository @ WVU with permission from the rights-holder(s). You are free to use this Thesis in any way that is permitted by the copyright and related rights legislation that applies to your use. For other uses you must obtain permission from the rights-holder(s) directly, unless additional rights are indicated by a Creative Commons license in the record and/ or on the work itself. This Thesis has been accepted for inclusion in WVU Graduate Theses, Dissertations, and Problem Reports collection by an authorized administrator of The Research Repository @ WVU. For more information, please contact researchrepository@mail.wvu.edu. 
Designing a Cultural Needs Questionnaire

Sabah Karayegen

Thesis submitted to the

Eberly College of Arts and Sciences

at West Virginia University

in partial fulfillment of the requirements

for the degree of

Master of Arts

in

Foreign Languages

Susan M. Braidi, Ph.D., Chair

Frank W. Medley, Jr., Ph.D.

Johan Seynnaeve, Ph. D.

Department of Foreign Languages

Morgantown, West Virginia

1999

Copyright Sabah Karayegen 1999 


\section{ABSTRACT \\ Designing a Cultural Needs Questionnaire}

\section{Sabah Karayegen}

This study describes the development of a cultural needs questionnaire intended to get a profile of foreign students' awareness of American culture. Specifically, the original questionnaire was designed to assess the level of awareness that English as a Second Language (ESL) students have of three aspects of American culture: family, gender roles, and education. The purpose of the development of student profiles resulting from this questionnaire was to offer one source of feedback to ESL teachers concerning these particularly relevant areas in which newly arrived students may be culturally confused. The piloting of the questionnaire revealed several problems inherent in the instrument which rendered it ineffective. The result of this research is a comprehensive re-design of the questionnaire, which can serve as a tool to measure ESL students' levels of cultural awareness. 
I do not want my house to be walled in on all sides and my windows to be stuffed. I want the cultures of all lands to be blown about my house as freely as possible. But I refuse to be blown off my feet by any.

Mahatma Gandhi

To my mother and father 


\section{ACKNOWLEDGEMENTS}

I would like to express my gratitude to Dr. Susan M. Braidi, who showed great patience in her guidance and instructions. She became my support in every way during this thesis, in which I learned a lot, and I accepted her as my role-model for her professionalism in my future career life. Sincere appreciation and thanks to my committee members Dr. Frank W. Medley, Jr. and Dr. Johan Seynnaeve for their constructive criticism of this study and their suggestions.

I would like to thank my mother who encouraged and supported me to become who I am in my long journey from Turkey to the U.S., and my father and my family who offered their endless support. I would also like to thank my American family, Rita and Charles Stockdale, my Turkish friends Özcan Mutlu and Ìbrahim Yavuz for their technical support, and my friends Francesca Hulin, Nilüfer Demirkan-Jones, and Andrea Lynn Marshall.

Finally, all of my thanks to the IEP students who participated in this study and to Helen Huntley and Dara Gay Shaw, who supported this research project. Without their cooperation, this research would not be completed. 


\section{Table of Contents}

Title Page

Abstract

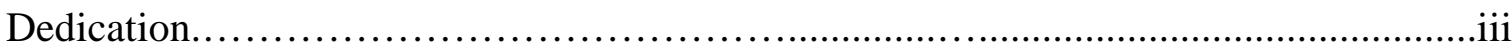

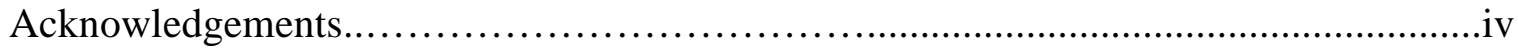

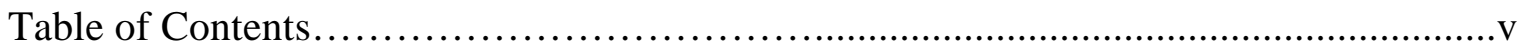

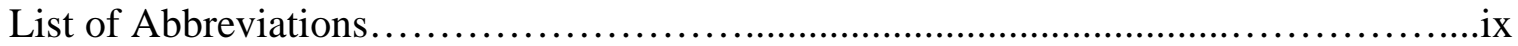

List of Tables ..................................................................................

\section{Chapter 1:}

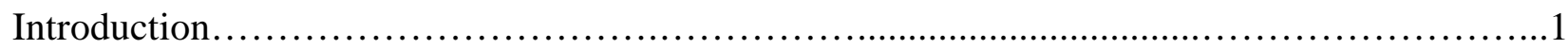

1.1 The Concept of Culture ................................................................

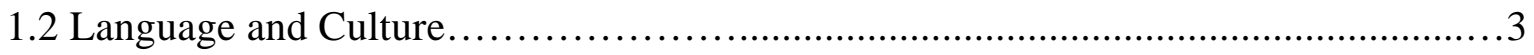

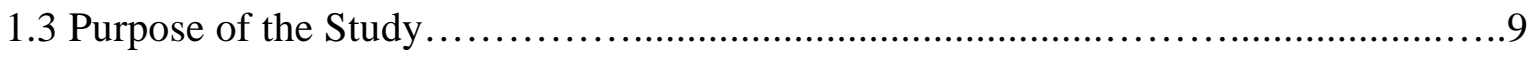

Chapter 2: Language and Culture.........................................................

2.1 Cultural Needs........................................................................... 14

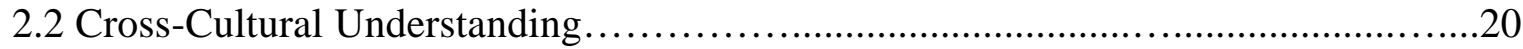

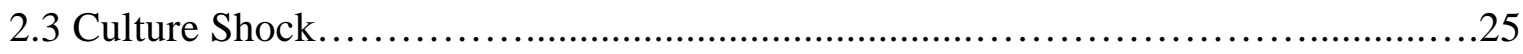

2.4 Social Distance and Language Learning................................................30

Chapter 3: Exploring American Values in the Cultural Domains of Family, Gender

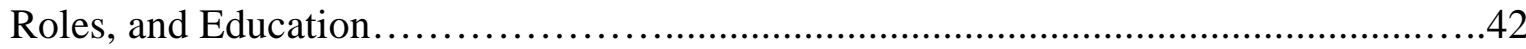

3.1 American Values........................................................................... 43

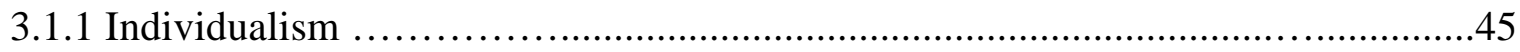




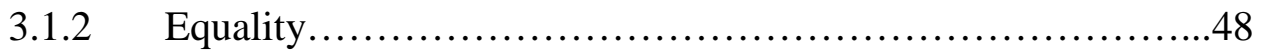

3.1.3 Materialism............................................50

3.1.4 Competition..............................................

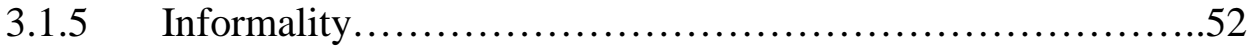

3.1.6 Directness and Assertiveness...............................53

3.2 Three Cultural Domains.............................................54

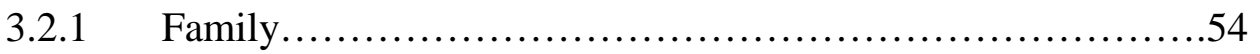

3.2.2 Gender Roles..........................................58

3.2.3 Education.................................................61

Chapter 4: Developing and Piloting the Questionnaire .............................65

4.1 Developing the Questionnaire...................................65

4.1.1 Demographic Questions....................................65

4.1.2 Native Culture Questions ..................................66

4.1.2.1 Individualism.................................67

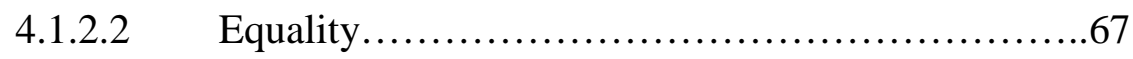

4.1.2.3 Competition...................................67

4.1.2.4 Informality...................................68

4.1.2.5 Directness and Assertiveness.......................68

4.1.3 American Culture Questions.................................69

4.1.3.1 Individualism...................................69

4.1.3.2 Equality......................................69

4.1.3.3 Materialism..................................... 70

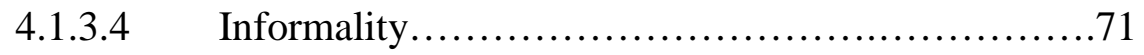


4.1.3.5 Directness and Assertiveness.....................71

4.2 Piloting the Questionnaire....................................72

4.2.1 Methodology........................................72

4.2.2 Results................................................. 72

4.2.2.1 Background Information....................... 72

4.2.3 Discussion............................................ 75

4.2.3.1 Background Information.........................75

$4.3 \quad$ Statistical Analysis.............................................. 77

4.4 Concluding Remarks.........................................77

Chapter 5: Characteristics and Validity of an Effective Survey Questionnaire..........80

5.1 Self-administered Questionnaires: Selection of an Administration

Format.......................................................... 80

5.2 Questionnaire Construction: Characteristics of an Effective

Instrument.........................................................

5.2.1 Content of the Questionnaire...........................83

5.2.1.1 Demographic Questions.......................83

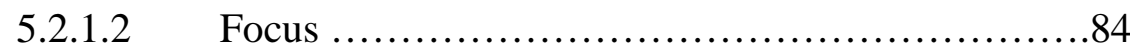

5.2.1.2.1 Question Items........................85

5.2.1.2.2 Response Items......................85

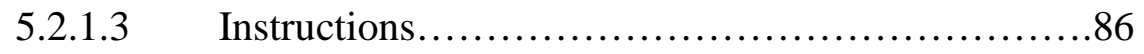

5.2.1.4 Format of the Questionnaire.....................87

5.2.1.5 Cover Letter................................... 88

5.3 The Formation of the Original Questionnaire.........................89 
5.3.1 A selection of a Format for Administration..................89

5.3.2 Questionnaire Construction...............................91

5.3.2.1 Content of the Questionnaire......................93

5.3.2.2 Question Items...............................93

5.3.2.3 Response Items.............................94

5.3.2.4 Cover Letter...................................95

$5.4 \quad$ Modified Research Design..........................................95

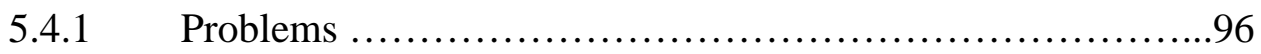

5.4.1.1 Problem I: Establishment of a Base-line or Control

Group.....................................96

5.4.1.2 Problem II: Selection of a Sample Population........96

5.4.1.3 Problem III: Design of the Questionnaire...........98

5.5 Modified Questionnaire.......................................98

Chapter 6: Conclusion.....................................................115

References............................................................ 119

Appendices................................................................ 123

Appendix A: Original Questionnaire......................................123

Appendix B: Tables..................................................... 135

Appendix C: Revised Questionnaire.......................................141

Curriculum Vitae........................................................149 
List of Abbreviations

C-1 Native Cultural Knowledge

C-2 Host Cultural Knowledge

ESL English as a Second Language

2LL Second Language Learning

TL Target Language

U.S. The United States

YMCA Young Men's Christian Association 
List of Tables

Table $1 \quad$ Levels of Cultural Awareness

Table B1 Nationality and Gender

Table B2 Age

Table B3 Educational Background

Table B4 Length of Stay

Table B5 Living With an American Roommate or Family

Table B6 Participation in American Activities

Table B7 Experiencing American Culture

Table B8 Usefulness of American Culture Courses

Table B9 Experiencing Cultural Misunderstandings

Table B10 Understanding of American Culture Concepts

Table B11 Similarity of the Expectations of Students' Own Culture to Those of the American Culture 


\section{DESIGNING A CULTURAL NEEDS QUESTIONNAIRE}

\section{CHAPTER ONE}

The connection between culture and second language learning and teaching has been studied over the past forty years by such language researchers as Schumann (1978a) Szalay and Fisher (1979), and Inglehart (1989). Although cultural comparisons are available in many sources (e.g., Nitsche \& Green, 1977; Althen, 1988; Seelye, 1993; Oxford, 1995), these comparisons are insufficient to prepare teachers and students for the cross-cultural learning experience. In particular, for teachers in intensive English programs, the difficulty that students have in adjusting themselves to the new culture soon becomes apparent. This adjustment problem affects not only their social lives, but also their language acquisition. Although teachers may be aware of the possible cultural differences, they often cannot determine how much of the necessary cultural awareness the students lack. One solution to this problem would be to develop a questionnaire to measure students' levels of cultural awareness. In this chapter, the concepts necessary to understand the connections between culture, language, and language learning are identified and defined. Within this context one approach to meeting the need for a greater understanding of learners' cultural awareness and to measuring potential deficits is described and discussed.

\subsection{The Concept of Culture}

Defining the concept of culture is very challenging. Since its meaning is very broad, it is hard to limit. In fact, Ned Seelye (1984) argues that it is better to describe culture rather than to define it. As can be seen in the discussion below, there are different approaches to characterizing culture. Allen and Valette describe culture as big "C" and 
small "c" (1994, p. 325). While big "C" represents people's achievements and contributions to their country like art, architecture, philosophy or literature, small "c" represents behavioral patterns or lifestyles of people such as when and what they eat or which traditions they must observe. We can learn about a country's big "C" by reading its history books or literature. On the other hand, learning about the small "c" requires a much more personal interaction with members of the culture. Wardhaugh explains culture as "whatever a person must know in order to function in a particular society" (1991, p. 211). Earlier, Goodenough maintained that "a society's culture consists of whatever it is one has to know or believe in order to operate in a manner acceptable to its members, and to do so in any role that they accept for any of themselves" (1957, p. 167). In other words, to understand a new country's culture, i.e., the small "c," it is essential to observe the host people in their cultural environment and interpret what is seen through the cultural template of that host culture.

A new country means a new world and a new culture. When foreign students come to the United States to learn English, no matter what their learning purposes are, they meet with a new world. The food, the language, the people, and the culture are totally new to them. Although some experiences and concepts may be similar to -- and interpreted as -- their own, they will recognize the differences much more easily. An awareness of these differences and their significance often determines the extent to which the visitor can interact successfully with the culture of the host country.

The extent to which one's own culture is assumed to be the norm is illustrated by Condon (1973). If a communication breakdown occurs between two foreigners, they are ready to "interpret any behavior which does not conform to their own life style as 
'contrary to the human nature' without realizing that the latter is not intrinsic to mankind, but is, instead, culturally conditioned and, therefore, variable" (p. 12). To avoid a communication breakdown or cultural misunderstanding, it is important to grasp the connection between language and culture. The following section will explain this connection in detail.

\subsection{Language and Culture}

Although language is a part of a nation's culture, culture cannot be understood without a language. Carley H. Dodd (1977) characterizes "culture" as follows:

1. Culture is not genetic.

2. Culture is not learned by individual experience alone, but socially.

3. Culture incorporates tradition handed down intergenerationally.

4. Culture involves symbols and code systems which are mediated by man's thought, perceived reality, senses and social relationships.

5. Language is the means of transmission.

6. Communication is a concomitant part of culture. It is both an antecedent and a necessary process for intracultural and intercultural relationships. It involves both message and channels, that is, the message content with its linguistic components and its symbolic relations and the networks of social transmission of information.

Although Dodd defined culture from the perspective of a native language, there are several implications that can be drawn from this definition to be applied to a foreign language learning setting as well as to a native language setting. Since culture is not genetic, it is possible to learn and to adjust oneself to a new culture. Therefore, it is 
possible for foreign students to understand and to adjust themselves to any new culture that they meet. If culture is formed by a group of people sharing the same values and beliefs, then it is a social learning experience where cultural negotiation occurs between the host culture member and the newcomer.

A native culture is learned in a family and is passed from one generation to the next. In the same sense, foreign students acquire the new culture from teachers at school, and from host members in their environment. To transmit a culture orally or in writing or to understand a culture, language is necessary, since language provides the means of transmission of the information. While a person's first language helps that person to be connected to his or her native culture, a foreign language gains importance for a newcomer in allowing him or her to live a healthy social life in a new host culture. In other words, language will help newcomers communicate with host culture members.

Some second language research makes even stronger claims concerning the interaction between culture and second language learning. For example, Schumann (1978b) claims that societal factors "either promote or inhibit social solidarity between two groups and thus affect the way a second language learning group (2LL group) acquires the language of a particular target language group (TL group) (p. 109). One of these societal factors is acculturation, and it is "a process in which changes in the language, culture, and system of values of a group happen through interaction with another group with a different language, culture, and system of values" (Richards, et al., 1993, p. 3). The more a learner acculturates, the more second language acquisition will be facilitated. The processes of acculturation can be described on a social-psychological distance scale. Based on Schumann (1978a), "social distance" is described by Richards, 
et al. as "the feeling a person has that his or her social position is relatively similar to or relatively different from the social position of someone else" (1993, p. 338). Similar to social distance, psychological distance is defined as "the result of various affective factors that concern the learner as an individual, such as resolution of language shock, culture shock, and culture stress" (1993, p. 110). In experiencing "language shock," the student "is haunted by doubts as to whether his words accurately reflect his ideas" and "when speaking the second language the learner has apprehensions about appearing comic, childlike and dependent" (Schumann, 1978b, p. 266). The student experiences "culture shock" when "he finds that his problem-solving and coping mechanisms do not work in the new culture" and this situation causes culture stress which is manifested by feelings of "disorientation, stress, fear and anxiety" (Schumann, 1978b, p. 266). The student may reject himself or the host culture as a result of attempting to find a cause for his disorientation. Language shock and culture shock affect the degree to which the students will acculturate in the new culture, and they may prefer to be distant to the new culture which results in negative social-psychological distance.

In addition, the phenomenon of culture shock can cause strong feelings of discomfort, fear, or insecurity. This period of initial contact with the host language and culture may result in quite traumatic experiences. Hanvey $(1979$, p. 53) explains the transition from one culture to another in four levels of increasing awareness, as is shown in the following chart: 
Table 1

Levels of Cultural Awareness

\begin{tabular}{|c|c|c|c|}
\hline$\underline{\text { Level }}$ & $\underline{\text { Data }}$ & Mode & $\underline{\text { Interpretation }}$ \\
\hline $\mathrm{I}$ & $\begin{array}{l}\text { Superficial } \\
\text { Stereotypes }\end{array}$ & $\begin{array}{l}\text { Tourism } \\
\text { Text }\end{array}$ & Exotic, Bizarre \\
\hline II & $\begin{array}{l}\text { Significant \& Subtle } \\
\text { Contrasts }\end{array}$ & Culture Conflicts & $\begin{array}{l}\text { Unbelievable, } \\
\text { Irrational }\end{array}$ \\
\hline III & $\begin{array}{l}\text { Significant \& Subtle } \\
\text { Contrasts }\end{array}$ & $\begin{array}{l}\text { Intellectual } \\
\text { Analysis }\end{array}$ & Believable \\
\hline IV & $\begin{array}{l}\text { Awareness as } \\
\text { Insider }\end{array}$ & Cultural Immersion & $\begin{array}{l}\text { Believable from } \\
\text { Objective Familiarity }\end{array}$ \\
\hline
\end{tabular}

Hanvey defines four stages of cross-cultural awareness, starting from tourist stereotypes and ending with living in the new culture. In Level I, information about the new culture may consist of superficial features, such as stereotypes. The newcomers see the new culture as bizarre and exotic. They focus on what the new culture lacks. Moving from a tourist level to the second stage involves the portrayal of cross-cultural differences through the experience of culture conflicts. Passing from the native culture to the host culture will result in frustration or irritation. At the second level, the newcomers only find the new culture irrational. They mainly focus on the differences between their own culture and the new culture, and they still find the new culture unbelievable and irrational. However, the subsequent process of intellectual analysis will help the newcomers to move from an irrational interpretation to cultural believability. At this stage (Level III), people realize that the new culture which was seen as irrational before, in fact, corresponds to reality. The new culture becomes believable since it can be explained. People begin to see the culture in terms of the target culture's frame of reference. The last level (Level IV) can be achieved through living in that culture. The newcomers begin to see the culture from the viewpoint of the host culture member, and 
are able to participate actively and appropriately in the environment and context of the host culture.

Hanvey (1979) defines this table by giving examples from Japanese culture. At level I, people might think that Japanese people are exaggerated in their politeness. At level II, through their direct or second-hand experiences, people find that the new culture traits contrast significantly with their own. At level III, people know that the aspect of the Japanese social hierarchy has nothing to do with politeness but is a mutual obligation between a superior and an inferior. At this level of cultural awareness, people accept this cultural trait intellectually because it begins to make sense to them (p. 53).

After actual contact with the host culture, some people may either move back to level II or up to level IV. Although level III is more attainable than level IV, realizing some aspects of level IV awareness is a worthy goal for English as a Second Language (ESL) students. If they are eager to understand the new culture, they begin to analyze the surrounding cultural traits. The experiences they find bizarre at the beginning may seem quite believable after a while. Finally, if they spend enough time, they may begin to see the similarities between the two cultures as well as the differences. They may start to understand how a member of the host culture feels because of their own subjective familiarity.

One can easily see a link between Hanvey's levels of cultural awareness and Schumann's notions of social and psychological distance. According to Schumann's research (1978a), the language acquisition of a student with a negative socialpsychological distance, i.e., who sees him- or herself as different from members of the host culture, will be lower than that of a student with a positive social-psychological 
distance, i.e., one who perceives the similarities between the two groups. Also, positive distance is proposed to accelerate language acquisition while negative distance may hinder that learning. He states as follows: "Second language acquisition is just one aspect of acculturation and the degree to which a learner acculturates to the targetlanguage group will control the degree to which he acquires the second language" (1978). In addition, the converse might be true. The more the students improve their language, the more they may become interested in the new culture. Within the new language, they may feel close to the new culture, imitating the members of the host culture. According to Hanvey's levels of cultural awareness, students who fail to adjust to the new culture are either in Levels I or II in which the host culture is seen as exotic, bizarre, unbelievable or irrational. Consequently, if their social-psychological distance is negative to the new culture, their desire to assimilate will also be low.

While Schumann's theories are based on the language learning of an immigrant in a second-language/second-cultural environment, international students in a secondlanguage/ second-culture environment would be faced with the same situation. In such a setting, students may also suffer from lack of cultural understanding, which may in turn result in increased social and/or psychological distance. For example, an Asian student attracts the waitress' attention by saying "Hey, waitress..." in a restaurant, while a Hispanic student might make a hissing sound with his mouth. Both of them may offend the waitress who is not used to these customer behaviors. Similarly, punctuality is cultural. The Mexican student who shows up twenty minutes late for his dinner appointment in the U.S. is considered by his or her American hosts to be inconsiderate or impolite, although to the Mexican the arrival is punctual. If the waitress or host is 
offended in these situations and rude in return, the visitors may easily draw the conclusion that Americans are not friendly at all. Neither may be aware of these cultural misunderstandings unless the members of the host culture advise them. Such experiences may increase the student's perception of negative social-psychological distance within the new culture.

\subsection{Purpose of the Study}

If Schumann's hypothesis about the relationship between language acquisition and cultural assimilation is true, then the question of what second language students need to know about the host culture and its people's perceptions of appropriate and inappropriate behavior and how to meet these expectations becomes a relevant factor in how to enhance their second language learning experience. What we as ESL teachers know about English may not be sufficient to make us successful in dealing with culturally different ESL students. One of the challenges faced by the ESL teacher is to help the students develop both cultural and linguistic skills that will enable them to function successfully in American life.

To help the students integrate and function successfully in American life, the ESL teacher must teach about the host culture from the very beginning. Culture can be an integral part of language instruction rather than an added frill. Language, which is a vehicle for explaining or expressing culture, is one of the primary and vital components of culture. To study the new language without studying the target culture can be boring for many students in the class. Some students want to learn about the new culture to bring life to their language learning (Scarcella \& Oxford, 1992, p. 184). Besides introducing the new culture into language classes to stimulate and maintain student 
interest in the new language, the role of the language teacher is to open the students' eyes to the target culture and to make them aware of the diversity that exists around them.

The language teacher's goal is not to replace the students' culture or language, but rather to broaden their cultural awareness. According to Allen and Valette, cultural goals of a language class should be categorized as increasing student awareness of the target culture, stimulating student interest in foreign language study, developing the ability to function in the target language, and establishing an understanding of linguistic referents, cultural values, and attitudes (1994, p. 326). By establishing an understanding of cultural values and attitudes, the teacher can help the students replace negative attitudes with positive ones. Students can reduce their stereotypes of the host culture. By correctly interpreting expressions, gestures or attitudes, students can interact harmoniously with the host people. As Mabbott states, "through culture, students discern the 'why' and the 'in order to' of the language to be studied and used" (1994, p. 22). In fact, failure to establish cultural meaning may actually inhibit the learning of language as a communicative tool.

The research reported in this study was intended initially to take a first step in the evaluation of students' cultural needs by developing a cultural needs questionnaire that would provide data that might help ESL teachers to understand their new students' cultural needs by generating a profile of their students' cultural awareness. This approach is similar to other types of analyses in which students' language goals and needs are evaluated. Since "culture" is a very broad area, the focus was upon a narrow list of cultural domains of immediate relevance to newly arrived students: family, gender roles, and educational issues. These domains were selected for several reasons. Students need 
to understand the family structure of the host culture, since families convey the values to their next generations. Therefore, understanding family structure will help the students understand the host culture values better.

Understanding the gender roles in the new society will give a direction to our students regarding what to do or how to treat members of the opposite sex. Based upon widespread reporting in the American press, it is reasonable to assume that the concept of gender roles has become very important in American culture since the 1960s when the push for racial, ethnic, religious, and gender equity became major political and ethnic issues, culminating in the passage into law of National Civil Rights Act of 1964. New terms, such as sexual harassment or social justice, confuse newcomers. Understanding the gender role patterns should inform students' roles, attitudes, and behavior patterns toward the opposite sex.

Most of our ESL students come to the U.S. to further their education through the pursuit of undergraduate or graduate degrees. Since it is a completely new educational system for them, most students run the risk of developing a feeling that they are incompetent or unfit in this new environment which they do not understand. Understanding the educational system in the U.S. will help the students compare and contrast the new one to their own. For these reasons, the questionnaire focused on the most relevant issues concerning family relationships, gender relationships, and teacherstudent relationships.

To sum up, the questionnaire was designed to assess the level of awareness that ESL students have of certain aspects of American culture. The domain of "family" was chosen on the grounds that family is one of the elements that shapes culture and its 
values. If students understand the family structure and its functioning in the new society, then it will be easier for them to understand the values of the culture. The domain of gender roles was examined since students are residing in a new society with different gender roles. Knowing what is appropriate or inappropriate behavior will eventually help students reduce the potential for misunderstandings that may occur between a newcomer and a member of the host culture. Education was explored through the questionnaire because most newcomers are students seeking their educational degrees in the U.S. and must be successful within that system.

Given the issues of culture and language shock and the proposed interaction between culture, social distance, psychological distance and second language acquisition, it is important for ESL teachers to have an accurate measure of our learners' cultural needs. The purpose of the development of student profiles resulting from this questionnaire was to offer one source of feedback to ESL teachers concerning these particularly relevant areas in which the students may be culturally confused. While other areas may also cause cultural confusion, due to the limitations of time and space, the proposed questionnaire was designed based on these three areas only. However, this questionnaire could be designed to include other cultural areas to fit the needs of the teachers and students. Other versions of the questionnaire might include cultural topics such as time, non-verbal communication, or food. For purposes of this study, however, the questionnaire was tailored to the issues of family, gender roles, and education within an ESL setting. The development of the study is as follows:

Chapter Two reviews the literature exploring the relationship between language, culture, and language learning. Chapter Three discusses the values behind the 
formulation of the questionnaire related to the chosen issues: family, gender roles, and educational issues. Chapter Four relates the particular American values to the individual questions in the questionnaire. Then, results of the pilot questionnaire are reported and discussed. In this study, the singular purpose of the questionnaire was to gather information about the respondents' perceptions of three aspects of American culture. Unfortunately, it soon became clear to the investigator that the questionnaire did not provide the information expected. As a result, the project shifted completely away from the original purpose -- collection of cultural data -- and focused on the problems inherent in the instrument itself that had rendered it ineffective. At that point, the researcher initiated a comprehensive re-design of the questionnaire in Chapter Five. It is this redesign that has become the objective of the study and the topic of the thesis. Finally, in the last chapter, the conclusions based on the results of the study will be drawn with the implications for further research. 


\section{CHAPTER TWO}

\section{LANGUAGE AND CULTURE}

In this chapter, the relationship between language and culture introduced in Chapter One will be examined in more detail. The relevant concepts include cultural needs, cross-cultural understanding, culture conflict and shock, social distance, acculturation, and language learning. Before building the bridge between language and culture, the researcher first discusses individuals' needs since people must satisfy their physiological and psychological needs in either their native culture or a foreign one. An awareness of how different cultures meet these needs may lead to cross-cultural understanding between a newcomer and a host culture member. Also related to crosscultural understanding are the concrete and subjective meanings of language, and cultural, cognitive, and affective factors. Before achieving cross-cultural understanding (which is an ideal that is hard to reach), the newcomer may face culture shock after his or her arrival in the new cultural environment. This culture shock will affect the degree to which a learner acculturates into the host culture. Failure to acculturate may, in turn, result in failure in language learning. These concepts and the connections between them will be explained and exemplified below.

\subsection{Cultural Needs}

Human beings must satisfy their basic needs such as food or shelter or clothing wherever they go (Maslow, 1970). These needs are the same for everyone; however, people in different cultures satisfy their needs in different ways. For example, shelter means a big family including grandparents in an apartment to a Turkish student whereas it may be a big house with a big yard and a dog to an American student. The order of 
importance of the needs and the way in which they are satisfied differ from one culture to another. In this section, the researcher will examine individual needs (Maslow, 1970) followed by an assessment of the needs that are likely to emerge in a classroom (Inglehart, 1989).

Maslow puts "physiological needs," such as food, at the top of the list of priorities. He states, "a person who is lacking food, safety, love, and esteem would most probably hunger for food more strongly than for anything else" (1970, p. 37). After satisfying our physiological drives, a new group of needs emerges. These so-called "safety needs" are security; stability; dependency; protection; freedom from fear, from anxiety and chaos; need for structure, order, law, and limits; strength in the protector; and so on. Maslow claims that

the average adult in our society generally prefers a safe, orderly, predictable, lawful, organized world, which he can count on and in which unexpected, unmanageable, chaotic, or other dangerous things do not happen, and in which, in any case, he has powerful parents or protectors who shield him from harm (1970, p. 41).

We can hypothesize that our foreign students feel that their safety is jeopardized by coming to a new world where this need for stability is challenged. Inglehart explains the same need as the "need for consistency" which is one of the affective factors in learning a new culture. Theories of cognitive consistency claim that "human beings have a basic need for cognitive consistency" (Inglehart, 1989, p. 33). They state that tension arises in a person's inner side when he or she gets new information which is inconsistent with his or her worldview. This tension motivates the person to re-establish his or her cognitive 
consistency. He or she can either shut out the inconsistent information or reorganize his or her current worldview to form a cognitively consistent picture. For example, our ESL students watch American sitcoms, or they read American magazines or, most commonly, they watch American movies, and they form their views about Americans based on this information. When these students come to the U.S., they see a side of this country that is different from the previously watched sitcoms or movies. At this point, to re-establish their cognitive consistency, they either shut out the inconsistent information, which may result in not engaging with the new culture, or they reorganize their current worldview as a result of interacting with and learning about the new culture.

Inglehart also suggests that teaching cross-cultural understanding in an ESL classroom will be actualized if this new material is presented as being connected to our students' worldview instead of a lot of new material as being inconsistent with it (1989, p. 33). Consequently, comparing and contrasting the host culture patterns to those of the foreign students becomes important at this point in teaching culture. However, expecting an ESL teacher to have an awareness of all of the different worldviews represented in a single class may not be a totally realistic goal since in an ESL class the students come from different countries and cultures. In a class with a homogeneous student population Inglehart's approach would be more feasible.

Once both physiological and safety needs are satisfied, "belongingness and love" needs will arise (Maslow, 1970). One can suppose that because international students are far away from their countries, this is the one which affects them the most. As an ESL teacher, the researcher has observed that some foreign students get depressed upon their arrival in the U.S. and they refuse to socialize with Americans. They blame this country 
and its people for their homesickness. On the other hand, after a while, if they establish new relationships with new people, they will satisfy their need to belong and to be loved. The hatred of the host country will be diminished by that time. Maslow's "belongingness" is similar to Inglehart's "need for identity" in that a student feels belongingness by being attached to his or her national identity. The latter claims that the need for identity gains importance especially in late adolescence since this is the period when the person's identity is shaped. One can develop a curriculum to teach successful cross-cultural understanding which is centered around the students' own national and cultural identities as well as the new culture. For example, discussing or having students make presentations about their own religious days in addition to Christmas or Easter in an American Culture class will honor our students because this approach makes them feel that they are not torn apart from their culture and identity.

In addition to physiological, safety, and belongingness needs, a healthy person needs to have "esteem." It is "a need or desire for a stable, firmly based, usually high evaluation of themselves, for self-respect, or self-esteem, and for the esteem of others" (Maslow, 1970, p. 45). Schumann explains self-esteem as "the degree of value or worthiness which an individual ascribes to himself" (1978c, p. 170). The emergence of this need is also applicable to our ESL students since they have difficulty both satisfying this need and learning a new language and a new culture at the same time in a new environment. Most foreign students initially do not want to participate in the ESL class (although it is usually very easy to find a couple of students who are very active in class). They are afraid of appearing childish or stupid in front of others. Since they want their classmates to have respect for them, they monitor their language to avoid making a 
mistake. They even avoid using the new language. Eventually, some of them fail to learn the new language due to low self-esteem. Scarcella and Oxford (1992) emphasize that "unsuccessful language learners - those who have particular problems in the language learning situation - have lower self-esteem than successful language learners" (p. 58). Sometimes the fear of not being really successful in learning the new language causes a learning crisis so uncompromising that the student may even lose the language ability he or she has already acquired.

Inglehart interprets the "esteem" need as a "need for ego defense." Ego defense theories emphasize a person's desire to establish a positive self-esteem. Meanwhile, interethnic hostility and other political attitudes can affect a learner's self-esteem and a need for self-defense may emerge. Schumann (1978c) also discusses this issue under the social factors in his research. He explains "attitude" as "if the 2LL [second language learning] group and TL [target language] group have positive attitudes toward each other, second language learning is more likely to occur than if they view each other negatively" (p. 166).

The satisfaction of the "esteem" need will lead "to feelings of self-confidence, worth, strength, capability, and adequacy, of being useful and necessary" (Maslow, 1970, p. 45). This theory holds that when a person reaches this level of satisfaction, then he or she will feel a need for "self-actualization" which refers to "a man's desire for selffulfillment, namely, to the tendency for him to become actualized in what he is potentially" (Maslow, 1970, p. 46). If a person is ultimately at peace with himself, he has to be what is in his nature. After satisfying the more basic needs such as physiological needs, students want to be engaged in their hobbies or their leisure activities. The 
researcher has observed that some foreign students feel miserable upon their arrival in the U.S. They do not want to participate in activities such as swimming, soccer, or tennis tournaments provided by their school or program. However, the same students begin to participate and enjoy the activities after a while as they establish their self-esteem and build their social environment.

In the self-actualization stage, students look for inconsistent and challenging information in class as opposed to their need for safety at the beginning. Inglehart explains the new need as the "need for stimulation." According to this factor, human beings also search for inconsistent information. This motivation, which is a need for new stimulation, is opposite in its effect from the need for cognitive consistency. Since human beings have short attention spans, naturally, they are interested in changes in their environment. According to Inglehart (1989), when teaching students in a peaceful classroom setting, stimulating material is essential to keep their attention. On the other hand, when accompanying students on a four week long round trip through the USA, an overload of stimulation is already offered from the environment (p. 33).

To conclude this section, it is important to note that this classification of basic needs creates a unity "behind the superficial differences in specific desires from one culture to another" (Maslow, 1970, p. 54). In other words, people are by nature alike because they share the same basic needs. The different patterns people follow to satisfy their needs confuse and often isolate the newcomers to a culture. Each culture determines which need comes earlier than others and how each need is satisfied for its members according to the cultural value and belief systems. How people will act in a 
certain situation or even what their goals in life will be are given direction by culture. Therefore, every individual's needs are shaped by the values of his or her own culture although physical and psychological needs are universal. Cultural differences in meeting these basic needs are highlighted in cross-cultural understanding and lack of crosscultural understanding.

\subsection{Cross - Cultural Understanding}

In order to understand the concept of cross-cultural understanding, we should first clarify what cross-cultural communication is. According to Levine and Adelman, crosscultural communication is a type of "communication (verbal and non-verbal) between people from different cultures; communication that is influenced by cultural values, attitudes, and behavior; the influence of culture on people's reactions and responses to each other" (1993, p. xvii). Cultural values, attitudes, and behaviors are different all over the world. However, effective communication depends largely on there being a shared cultural context. Thus, two people belonging to two different cultures may have difficulty communicating if their cultural referents do not match.

We observe miscommunication examples every day even in our native language and culture, so it is very natural to be misunderstood in a second language context due to different cultural beliefs and attitudes. In addition to the language problem, the intention attached to cultural expectations creates another problem. Szalay and Fisher also note that "making a transition from one language to another actually involves going from one culture world to another" $(1979$, p. 60). They identify the first problem that should be overcome in this transition in order to avoid a misunderstanding as "egocentric bias." This bias involves 
the tacit assumption that if we say something that makes good sense to us, it should make sense to everyone else--a bias that is about as unrealistic as it is widespread. In some cases in our own culture, as when talking to children or to mental patients, we are more aware that our statements may not be automatically understood (1979, p. 61).

Accordingly, when a communication occurs between the native and nonnative speaker, the native speaker often assumes that the nonnative speaker understands him or her completely. However, most nonnative speakers experience both linguistic and cultural miscommunications. Therefore, understanding the correlations between learning a foreign language with the aim of attaining communicative competence and the process of understanding the American culture gain importance for an ESL teacher to prevent his or her students' potential misunderstandings.

How our students understand and form their attitudes toward the new culture can be attributed to their direct or indirect experiences. The direct contacts "need to be long sustained, voluntary, and on an equal status basis in order to lead to positive attitudes" (Inglehart, 1989, p. 29). Schumann's research (1978c, p. 165) results in a similar finding: if the second language learning group is politically, culturally, technically, or economically inferior (subordinate) to the target language group, it will tend not to learn the target language.

Processing of the new cultural knowledge is analyzed by Wolff (1989), and it is assumed that human information processing is universal. Therefore, we cannot expect first and second language processing to show any substantial differences. However, a student's native culture has an effect on his second culture acquisition. Wolff cites 
Steffensen and Joag-Dev's (1984) research which shows that the role of native cultural knowledge (C-1) is so important that it even distorts host cultural knowledge (C-2) in a given text or utterance. This research, which was a cross-cultural analysis of reading comprehension, included twenty Americans and twenty Indians. They were exposed to two variants of an English text which describes a marriage. One of the texts presents a typical Indian marriage while the other describes a typical American ceremony. The Indians had to process the American ceremony version, and the Americans were given the Indian version. Both groups recalled the story after processing. The results show that "the knowledge components of one's own culture strongly influence the processing of a text" (p. 234). This cross-cultural experimentation suggests that reading comprehension is a function of cultural background knowledge. If the readers cannot process the text, they distort meaning as they attempt to accommodate it to their pre-existing knowledge structure. Although the readers did not process the texts in a foreign language, the results still address the question of whether or not the native cultural knowledge influences language processing. The results reveal that a person's native cultural background influences "the acquisition of C-2 cultural knowledge because this knowledge is processed through the filter of the first culture and is, therefore, in most cases distorted" (p. 236).

People in every country develop their own cultural beliefs or attitudes. It is hard to predict or define them since they are not available in dictionaries or books (except for certain textbooks on culture). These beliefs and attitudes create differences in cultures, and tuning in to these differences for a newcomer is essential in order to communicate successfully across the cultures and, of course, languages. 
People must realize that cultural differences do exist, and they cannot assume that the foreigners' translations of their ideas in the new language will convey the same meaning. The concrete meanings in a communication can be understood, but the subjective meanings associated with their culture will produce different patterns of reference. An example of these subjective meanings is given by Lado (1963). For example, the word "cruel" will carry different connotations in English compared to Spanish. Connected to cruelty, "bullfighting" is a source of cross-cultural misunderstanding. Lado (1963) chose this cultural occurrence as a case study. In his study, the meaning of bullfighting is investigated through the interpretation of a Spanish and of an American spectator. It is a sport that displays bravery and symbolizes "the triumph of art over the brute force of a bull" in Spanish culture (Lado, p. 115). On the other hand, the meaning of bullfighting is quite different to an American. He thinks, "it is the slaughter of a 'defenseless' animal by an armed man" (p. 115). It is cruel to the bull since it is always killed in the end. Therefore, the fighter and the spectators are cruel, too. In this example, what is seen as bravery in one culture is defined as cruelty in another. While the American calls this case cruel, the Spaniard will never make the connection between "cruelty" and "bullfighting."

Culture is also reflected in the language as Lado (1963) exemplifies in his study. For example, both "animals" and "humans" have legs in English. However, in Spanish, "animals" have patas 'animal legs' and "humans" have piernas 'human legs"” (p. 116). We can amplify the additional features of difference by questioning what an animal means to a Spaniard and to an American. In Spanish culture, a man is skillful and intelligent unlike a bull, which is only superior in physical strength. However, in 
American culture a man is strong, as is a bull. Moreover, from the American perspective, the bull is intelligent and has feelings such as pain or sorrow. So "a bull deserves an even chance in a fight; he has that sportsman's right even against a man" (Lado, 1963, p. 117).

As these examples demonstrate, to avoid a cross-cultural misunderstanding in a new culture, language teachers and learners have to deal with both the language and the culture. Our students have to learn to comprehend the new culture in the new language. Therefore, cultures can be discussed to improve students' cultural awareness during the process of learning the new language.

Some ESL teachers do not feel comfortable talking about culture in their classrooms. Their lack of knowledge about what to say and what to avoid creates the problem (Omaggio, 1986, p. 361). This ignorance may promote ethnocentrism, which hurts our students more than does saying something wrong about their culture in comparison to the new one. Instead, teachers should be able to talk about cultural patterns in order to develop an understanding of a foreign language and culture.

While cross-cultural understanding occurs between people from different cultures, the differences in beliefs or attitudes create differences in cultures, which results in the necessity of the comprehension of the new culture in the new language. Students must develop a cross-cultural awareness if they are to successfully acquire a second/foreign language, since this cross-cultural understanding will help them communicate with host culture members. Achieving a good level of language acquisition and being a part of that culture can interchangeably affect each other, either negatively or positively. In a negative interaction, the possible interpretation ambiguities, some of which are shown above, may cause culture shock to the newcomer due to cultural differences. In the 
following section, culture shock and its relation to second language learning will be defined and discussed in detail.

\subsection{Culture Shock}

Culture shock refers to "a removal or distortion of many of the familiar cues one encounters at home and the substitution for them of other cues which are strange" (Hall, 1973, p. 174). The following personal experience illustrates my own confused feelings and values as a Turkish newcomer in a strange land due to a challenge to my beliefs. In Turkey, we always consult other people in making a decision such as buying a new car or changing jobs. The oldest family member takes the responsibility for making decisions for other younger relatives. With reason, the first time I was in the U.S., I was quite shocked to see young American children bossing around their families. I called it disrespectful at the beginning. While I was working as a baby-sitter in a YMCA camp, I wanted to treat the children as I would in Turkey. Of course, my problem-solving strategies did not match those of American families. I tried to understand the concept of individualism by again consulting my friends. I still remember my friend saying, "Americans bring up their children as if one day these children will become the president of the U.S." It was a strong, but a very true claim. However, in my culture, some family elders even choose a wife for their son.

In this baby-sitting example, I was challenged by the new concept of "individualism." The way the children acted would be considered quite disrespectful in my country while it was a sign of independence in American culture. It was difficult for me to change my existing beliefs or at least to understand and accept the new ones. In a new country, we learn different patterns of living and see common events from new 
perspectives. This is a challenge to our assumptions about what is "right" or "wrong." This baby-sitting experience is only one example of many confusing incidents that might happen to a newcomer in a single day.

As is seen in the example, whenever two cultures come together, conflict occurs. Seelye argues that this is "because of a clash of values - a cultural difference in the perception of the appropriate way to satisfy basic physical and psychological needs" (Seelye, 1993, p. 57). Barlund (1985) observes that "Repeated collisions between a foreigner and the members of a contrasting culture often produce" culture shock and the person feels "helpless and trapped in a nightmare" (p. 12). This view is further strengthened by Oberg (1972) who argues that culture shock "might be called an occupational disease of people who have been suddenly transported abroad... [it] is precipitated by the anxiety that results from losing all our familiar signs and symbols of social intercourse...." (p. 43). According to Oberg (1972), "No matter how broadminded or full of good will you may be, a series of props have been knocked from under you, followed by a feeling of frustration and anxiety" (p. 43).

Oxford states, "There are two major views of culture shock: the disease view and the self-awareness view." (1995, p. 25). In the "disease view," students experience a breakdown in communication. They feel lost and isolated. They are not able to cope with emotional and mental difficulties. They become angry and frustrated. Full of frustration, these newcomers reject the environment that causes the discomfort. Feeling helpless, they call the ways of the host country bad since these customs make them feel bad. Some culture-shocked students may even avoid physical contact with the host culture members. They feel "contaminated, tricked, deceived, injured, or ignored" 
(Oxford, 1995, p. 25). They may also become physically ill such as having ulcers or headaches or more. What really affects their language acquisition is their "reduced personality," as Oxford (1995) explains it. With this personality, the students cannot speak the language very well, and therefore their communication will be limited. They will not be able to express themselves, including their personal feelings and psychological needs. Since they cannot communicate with the others, they will feel childish, which may result in shame and anger.

On the other hand, this experience may have a positive side, which is called "the self-awareness view of culture shock." Adler (as cited in Oxford, 1995, p. 25) proposes that positive cross-cultural learning experiences typically:

- involve change and movement from one cultural frame of reference to another;

- are personally and uniquely important to the individual;

- force the person into some form of self-examination;

- involve severe frustration, anxiety, and personal pain, at least for a while;

- cause the person to deal with relationships and processes related to his or her role as an outsider;

- encourage the person to try new attitudes and behaviors; and

- allow the person to compare and contrast constantly.

In the self-awareness view of culture shock, the students learn to communicate, even though they are making mistakes in public or feeling awkward most of the time. This positive experience will help them reduce their anxiety and use the contact with the host culture as an opportunity for growth. 
As is seen in the division of "the disease view" and "the self-awareness view," "individuals differ greatly in the degree in which culture shock affects them" (Oberg, 1972, p. 44). Some may leave the country shortly after their arrival. For others, it takes a step-by-step process to overcome the culture shock and to reach a satisfactory adjustment to the new culture.

Comparable to the newcomers or tourists in a new country, our students are also impressed by "the new" around them in the U.S. in the first couple of weeks. However, the fascinating days do not last long, and our students begin to complain about the host country. In this stage, if the second language teachers help their students gain some knowledge of the language and the culture, they are more likely to learn to cope with the difficulties more easily.

"It is critical to acknowledge that to penetrate another culture, knowledge of the foreign language is imperative" (Seelye, 1984, p. 14). Besides being a key to enter a new culture, different usage of language must be taught to avoid a miscommunication between a newcomer and a host country member, as Seelye states. The following illustration shows this language and miscommunication dilemma. Students do not always have the flexibility to recognize that one grammar item may have more than one meaning or one function. For example, the researcher has seen that new students misunderstand the usage of "should" in different contexts. If they assume "should" is a modal that shows only a command, they will be easily offended when it is used in a context to give advice. A student who is moving out can be a good example. In some countries, people do not have to clean their apartments carefully before they move out since preparing it for the new tenant is the landlord's responsibility. When a foreign student mentions to his 
American friend that moving out will be easy for him since he will just pack and leave, a responsible American friend may say, "You should clean your apartment before you leave." The foreign student gets offended and at the same time feels humiliated. Obviously, the American friend shows good will by just giving advice, but a statement such as "If I were you, I would..." seems offensive and humiliating. The student's lack of language and cultural understanding at this point hurts a relationship.

If culture shock may be directly linked to the language our students use and to the culture that surrounds them, the teacher should be able to combine the two competencies (i.e., culture and language) in the same curriculum to avoid such misunderstandings as are seen above. If the teachers succeed in improving their students' cultural awareness in addition to their linguistic competence, the students even start to enjoy experiencing the new. The more they enjoy learning the new culture, the more they get involved with the host culture and the host people, of course. In return, they interact in the target language more, which helps them improve their communicative and linguistic competence.

In sum, whenever two different cultures come together, conflicts occur which result in the newcomer's "culture shock." This culture shock may end in either the disease view or the self-awareness view. As is seen in the "disease view," culture shock not only affects the student's ability to function in the new culture, but it also influences the student's psychological and physical condition. Moreover, it affects the learner's ability to use and learn the language. Later, a newcomer who has exhibited the features of the disease view may overcome his or her culture shock and experience cultural selfawareness. The connection between culture shock and language learning which exists in both views is highlighted in the next section; the students' involvement with the host 
culture, which can be measured on a social distance scale, will be discussed with respect to its relationship to language learning.

\subsection{Social Distance and Language Learning}

Schumann's (1978b) research reveals that societal factors either "promote or inhibit social solidarity between two groups and thus affect the way a second language learning group (2LL group) acquires the language of a particular target language group (TL group)" (p. 261). He claims that the greater the social distance between the two groups, the more difficult it becomes for the 2LL members to learn the second language. He lists the following features that help define social distance:

1. Dominant: 2LL group is politically, culturally, technically or economically superior to the TL group.

2. Non-dominant: 2LL group is politically, culturally, technically and economically equal to the TL group.

3. Subordinate: 2LL group is politically, culturally, technically and economically inferior to the TL group.

4. Assimilation: 2LL group gives up its own life style and values and adopts those of the TL group.

5. Acculturation: 2LL group adapts to the life style and values of the TL group, but at the same time maintains its own cultural patterns for use in intra-group relations.

6. Preservation: 2LL group rejects the life style and values of the TL group and attempts to maintain its own cultural pattern as much as possible. 
7. Enclosure: The degree to which the two groups have separate schools, churches, clubs, recreational facilities, professions, crafts, trades, etc.

8. Cohesiveness: The degree to which members of the 2LL group live, work and socialize together.

9. Size: How large the 2LL group is.

10. Congruence: The degree to which the cultures of the two groups are similar.

11. Attitude: Ethnic stereotypes by which the two groups either positively or negatively value each other.

12. Intended length of residence: How long the 2LL group intends to remain in the TL area. ( p. 261)

Schumann's research (1978c), which explores the relationships between language acquisition and social factors, presents the idea that if second language learners are politically, culturally, technically, or economically dominant to the target language group, they will tend not to learn the new language, and they will be socially distant from the new culture. This is also true in a situation in which the second language learning group is subordinate to the target language group.

As is discussed in the first chapter, assimilation fosters minimal social distance, and preservation causes social distance to be maximal. Second language learning is facilitated by assimilation and hindered by preservation. Acculturation, the social and psychological integration of the learner with the target language group, falls in the middle of the two. Schumann (1978b) has suggested that the learner will acquire the second 
language only to the degree that he or she acculturates, and that there are certain variables that either promote or inhibit the contact and interaction between the two groups.

Social and affective variables can explain Schumann's (1978a) case study of a 33year-old Costa Rican immigrant, Alberto, who showed a lack of progress in second language learning. Alberto, who was a Latin-American working class immigrant, was seen as socially and psychologically quite distant from the target-language community. He preferred to be with his Spanish-speaking friends rather than with Americans. He did not have a TV, and he preferred to work all day rather than attend English classes. A 9month study showed that Alberto had very little linguistic development. A Piagetian test of adaptive intelligence, which was conducted in Alberto's native language, proved this failure was not because of a cognitive deficit. Because his social-psychological distance was negative, Schumann concluded that Alberto's motivation to learn about the new culture and to assimilate into it affected his acquisition negatively and resulted from minimal acculturation to the target language group.

According to Schumann's study, Alberto represented an unskilled labor group whose socio-economic status was lower than that of Americans. The worker immigrants in the U.S. are between preservation and acculturation relative to their desire to integrate into American society. In terms of enclosure, Spanish-speaking people have an access to the American institutions -- being both Western and Christian -- compared to other nationalities. However, these immigrant communities prefer to go to their own churches or schools in their immigrant neighborhoods. Alberto showed these same behaviors and stuck close to his Spanish-speaking friends. 
Alberto was given a questionnaire concerning his attitude and motivation in order to measure his psychological distance to the new culture. His answers revealed that he had had a positive attitude and good motivation, however his answers may reflect what the experimenters wanted to hear. There are several aspects of Alberto's life style that appear to conflict with his positive attitude and motivation, such as spending little effort to get to know Americans, having no TV (he expressed his disinterest in buying one since he could not understand English), but buying an expensive stereo to listen to Spanish music. He also preferred working at nights rather than going to English classes. His negative social and psychological distance from the American culture resulted in lack of progress in learning English.

Although Schumann's model is more a model of language non-acquisition than language acquisition, this model helps us clarify the potential negative effects of distance factors. He claims that certain social and psychological factors can either promote or inhibit contact between the host members and the learning group and thus affect the degree to which the second language learning group acculturates that in turn affects the degree to which they will acquire the new language. Acculturation is the social and psychological integration of the learner with the target language group. The learner will acquire the second language only to the degree that he acculturates. Acculturation is also influenced by affective variables, such as language shock, culture shock, and motivation as discussed previously.

The issues involved in social and psychological distance and discussed above for immigrants can be applied, this researcher believes, with some modifications to ESL students, although their learning conditions are different. Therefore, the issues explained 
and exemplified above by Schumann may also form a basis for language teachers to understand the situations of their foreign students, as argued below.

While immigrants may learn English over a long period of time, ESL students often pay for their language program and have a limited time to learn English. In addition, most immigrants have financial and family issues to deal with related to survival in the new cultural environment. They have to work and support their family while most students are supported by their families. An additional issue is the expected length of stay in the new country. Immigrants have long-term goals such as finding a job and becoming a citizen in contrast to the short-term goals of ESL students who come to the U.S. only for their educational goals.

In relation to Schumann's characteristics of dominance, non-dominance, and subordination, the students may feel politically, culturally, technically, or economically superior, equal, or inferior to the American culture. For example, Peñalosa (1980) points out that "if language minority students are made to feel inferior because of accent or language status, they may have a defensive reaction against English and English speakers" (as cited in Díaz-Rico and Weed, 1995, p. 27). The notions of assimilation, acculturation, and preservation may also affect the foreign language students' language acquisition. For example, a student who is willing to interact with American students socially will probably have a high possibility to acquire the new language faster than a student who wants to socialize exclusively with his or her compatriots.

Enclosure, which is another social variable, refers to the degree to which the students and the host country members share the same places and activities. If the two groups share the same churches, schools or similar facilities, enclosure will be low and 
the students' acquisition will be facilitated. For example, many Moslem students in the U.S. have fewer social advantages compared to European students who share the same Christian churches with Americans; as a result, the contact between Moslem students and Americans may be more limited. While European students have a chance to join American celebrations in a church or any other organization at Christmas or Easter time, Moslem students celebrate their holidays by themselves in their homes or mosques.

Cohesiveness and group size also affect our students' language acquisition. If their "intragroup contact will be more frequent than intergroup contact, their opportunities for acquisition of the target language will be reduced " (Schumann, 1978c, p. 166). Personal observations lead the researcher to conclude that foreign students tend to associate with the people who speak their native language. For example, Spanishspeaking students go out together although they are from different countries such as Colombia or Spain while Arabian students from Saudi Arabia or Kuwait do the same. Although different groups sometimes participate in activities together such as soccer tournaments or parties, the groups still tend to remain separate from the target group. Congruence or similarity between the native culture and the host culture also determines the degree of contact between the two. If the two cultures are similar, according to the theory the contact and therefore the students' acquisition of the second language will be facilitated. If the two cultures show too many differences, the ESL teacher can help to shape the students' interpretation of these cultural differences. Finally, how long the language learner intends to remain in the target language area will determine how much contact will occur between the two cultures. If the language learner 
stays for a long period, the length of residence may promote language learning due to more extensive contact.

These social variables -- dominance, non-dominance, subordination, assimilation, acculturation, preservation, enclosure, cohesiveness, size, congruence, attitude, and intended length of residence -- determine the degree to which the students will be integrated into the new culture and correspondingly, will be involved in the second language acquisition process. Although a student may learn under social conditions which are not appropriate for language learning or not learn under appropriate conditions, Schumann's research gives us one explanation for our students' possible lack of development in their language acquisition process. In summary, while there are differences between an immigrant and a student population, both groups are foreigners who have to learn a new language and culture in a new country.

Acculturation is also influenced by affective variables, such as language shock, culture shock, and motivation as we have seen above. The students may "shut themselves off from the classroom society, and they may resist trying to contribute their own output to the class" due to a negative social-psychological distance to the new culture (Mabbott, 1994, p. 18). A responsive teacher minimizes the potential negative effects of distance variables. As discussed previously, if the language learning group and the host group have positive attitudes toward each other, second language learning is more likely to be facilitated than if they have negative attitudes. This relationship between language and culture emphasizes the importance of teaching culture as a means of building a bridge between the two to enable students to pass from one culture to another. 
Although Schumann's social-psychological distance model is twenty years old, a number of researchers studying second language acquisition following Schumann's study have also explored the relationship between social factors/acculturation and the degree of success in learning the target language, and have reported somewhat different findings and conclusions. One example is Andersen's Nativization Model (1983). In his model, Andersen stresses to a great degree the role of internal processing mechanisms, i.e., nativization and denativization. Nativization refers to the "learner's tendency to make new input conform to his or her 'internal norm', or mental picture, of what the L2 grammar is like" (Larsen-Freeman \& Long, 1991, p. 265). Denativization, on the other hand, refers to the "learner's adjustment of his or her IL system in the direction of his or her mental picture of the target, or 'external norm' (Larsen-Freeman \& Long, 1991, p. 265). While he is less concerned than Schumann with defining the social and psychological factors, he does agree with Schumann that a combination of "negative" social and psychological factors leads to restricted access to the second language and its culture (McLaughlin, 1991, p. 113). Another model which examines social variables is the Zisa Project reported by Meisel, Clahsen, and Pienemann (1981). Their efforts were to link social-psychological and linguistic aspects of second-language development. In their model, "the learner's position relative to the target language is defined by two dimensions: the learner's developmental stage and the learner's social-psychological orientation" (McLaughlin, 1991, p. 114). They proposed that "learners vary along a continuum that ranges from a segregative to an integrative orientation, depending on how favorably they are disposed to speakers of the target language" (p. 114). These models also acknowledge the influence of social and psychological factors on language 
development to varying degrees. Although they are not based specifically on Schumann's pidginization model, according to McLaughlin (1991, p. 109), this work has been "greatly influenced" by Schumann's (1978a) model.

While further research has been influenced by and continued to extend Schumann's early studies concerning the social-psychological impact on language acquisition, mention must be made of three questions of concern by Brown (1987), and McLaughlin (1991). Brown questions Schumann's theory in terms of how social distance can be measured and how one can accurately assess the degrees of social distance. Further, he asks "how would those means be quantifiable for comparison of relative distances?" (Brown, 1987, p. 133-134). Brown feels that this construct is rather subjective and therefore unable to be reliably measured beyond one's intuitive sense. Acton (1979), however, had previously addressed one as part of this issue by proposing a solution to this dilemma. Acton devised a measure of perceived social distance rather than measuring actual social distance stating that "it is not particularly relevant what the actual distance is between cultures, since it is what learners perceive that forms their own reality" (p. 134). He devised the Professed Difference in Attitude Questionnaire (PDAQ) which characterized the "good" or successful language learner quite accurately but failed however to predict success in language. But, what the PDAQ did, however, "was to describe empirically, in quantifiable terms, a relationship between social distance and second language acquisition" (p. 134).

McLaughlin (1991) raises the further questions of variability and causality. Concerning variability, in spite of the "dynamic" orientation of the Acculturation model, he feels that "relatively little attention has been given to the possibility of changes in 
individual motivation and attitude as they relate to second language acquisition" and the changing nature of these factors is not emphasized (pp. 125-126). In addition, McLaughlin questions the Acculturation hypothesis, as reflected in Schumann's notions of social and psychological distance which "assumes a causal model in which attitude affects access to input which in turn affects second-language acquisition" (p.126). McLaughlin believes, however, that there could be a possibility, "that the line of causality, rather than going from attitude to second-language acquisition, goes in the opposite direction. Successful learners may be more positively disposed toward the target-language group because of their positive experience with the language" (p. 126). In other words, McLaughlin sees a bi-directional relationship between the attitude of a language-learner and his or her attitude towards the target culture, and/or their second language acquisition success, whereas Schumann only addresses the second language learner's attitude towards the target culture.

With regard to this pilot study, Brown's and McLaughlin's concerns and questions about the possible weaknesses in Schumann's theory do not appear to be problematic in basing the current study on Schumann's social and psychological distance theory. First, regarding Brown's concerns of how actual social distance can be measured, this study is attempting to design a questionnaire to get a profile and assessment of preconceived notions of American culture, not of social distance.

McLaughlin's concerns of "variability" and "causality" also appear not to be problematic, due to the fact that the proposed questionnaire will be administered to newly arrived students upon beginning their studies abroad as a needs analysis tool. While it is certainly true that individual learners exhibit changes in motivation and attitude, and that 
the influence of motivation and language learning success may be bidirectional, the cultural needs questionnaire can provide a starting point from which teachers proceed in their culture and language teaching. The purpose of the questionnaire is to measure cultural awareness; it is not intended as a means of identifying the causes of motivations or attitudes.

The latter concern of "causality" would further seem not to apply because the proposed questionnaire as a measure of cultural awareness does not address the issue of the effect of cultural awareness on proficiency. While the Acculturation model is based on the interrelation between culture and language learning, a student with a positive attitude to the new culture may still misinterpret an American behavior. At that point, the teacher who determines such misinterpretations from the student's assessed profile can work this cultural content into the class curriculum. By the same token, a student who is good at verbal skills may interpret an American behavior wrongly and may reflect it on the proposed questionnaire. The teacher, again, will be able to get this profile information via the questionnaire and choose to alter the curriculum accordingly. Therefore, the problem of causality being one-way or bi-directional does not apply to this study because the proposed questionnaire should reflect the students' profile regardless of their feelings about the language or the culture. Therefore, the fact that this study is based on Schumann's theory merely acknowledges that language and culture both play an important role in second language acquisition.

This review of the issues involved in language and culture learning has highlighted the importance of culture in second and foreign language acquisition. The issues discussed in this chapter have an intricate interrelation with each other. The ways 
in which different cultures deal with cultural needs may confuse newcomers, specifically in terms of identifying which needs have priority over others and how each need is satisfied for its members according to the cultural value and belief systems in the new culture. These changes in value and belief systems may cause problems in cross-cultural interaction. Furthermore, the lack of cross-cultural understanding can cause culture shock which blocks students' linguistic and communicative intentions. This blockage can affect the students' social and psychological distance in relation to the new culture and the new language. Negative distance, in turn, can negatively affect the students' learning the new language and adapting into the new culture. Therefore, evaluating our language learners' cultural needs is more an imperative than an option, and the development of a cultural needs questionnaire is the logical next step. 


\section{CHAPTER THREE}

\section{EXPLORING AMERICAN VALUES IN THE CULTURAL DOMAINS OF FAMILY, GENDER ROLES, AND EDUCATION}

Foreign students' lack of cultural awareness in a new culture can have an effect on their language acquisition. Therefore, understanding the students' cultural needs becomes an important prerequisite in helping students to integrate and function successfully in American life as well as to learn the new language. However, students' cultural needs are not often, if ever, evaluated. One solution to this gap in necessary information is the development of a cultural needs questionnaire that would provide the relevant data.

In the design of such a questionnaire, it is first necessary to select the targeted topic domains which the questionnaire will explore. In the case of a cultural needs questionnaire, the specific cultural domains and their underlying values must be selected and examined. Because people from the same culture share similar values, they evaluate their environment, such as events, people, and their behaviors, based on these values. In this chapter the researcher will first explore a selected subset of American values -individualism, equality, materialism, competition, informality, and directness and assertiveness --, and then discuss how these values are manifested in three domains of American culture: family, gender roles, and education.

This subset of American values is chosen for two reasons. First, the values repeatedly appear in American culture textbooks (Althen, 1988; Datesman et al., 1997; Jason and Posner, 1995; Levine and Adelman, 1993). Second, these values are the particular ones which underlie the three cultural domains of family, gender roles, and 
education selected for this study. These domains are used to prepare the questionnaire due to their importance in meeting learners' basic socio-cultural needs.

First, the domain of "family" is included on the grounds that cultural values are transmitted within the family structure as stated in Chapter One. If students understand the family structure and its functioning in the new society, then it will be easier for them to understand the values underlying this family structure. Secondly, the domain of gender roles is examined since students are expected to function in a different (largely unfamiliar) society with new gender roles. Knowing what is appropriate or inappropriate to do will eventually help students avoid the potential misunderstandings that may occur between a newcomer and a member of the host culture. For example, the researcher has observed that some foreign students are not aware of the degree of female-male equality in this culture. Consequently, some male students who come from a society in which a man dominates a woman cannot easily adapt themselves to the new gender roles. They find it difficult when a woman asks a man to do something such as when a female secretary at a college asks a male foreign student to do something. Therefore, discussing gender roles in American culture will eventually help students understand how gender roles function in this society. Finally, education will be explored through the questionnaire because most newcomers in intensive English programs are students seeking their educational degrees in the U.S., as previously stated.

\subsection{American Values}

“' 'Values' are ideas about what is right and wrong, desirable and undesirable, normal and abnormal, proper and improper.” (Althen, 1988, p. 3) They shape people's attitudes and cultural patterns. Although there are no absolute rights and wrongs, these 
attitudes and cultural patterns tend to define cultural differences. For example, Americans value their space and keep a personal space surrounding them. They even measure the space by saying "stay at least an arm's length away" or even sometimes use three feet as a measure (Althen, 1988, p. 38). Consequently, if two men hug or kiss each other in public or simply walk arm in arm, this behavior may be seen to be representative of a homosexual attraction to each other. Stewart explains it as, "the close proximity Latins or Arabs prefer while conversing disturbs Americans, since physical nearness carries either sexual or belligerent meaning" $(1985$, p. 52). On the other hand, in many Asian and Arabic countries kissing or hugging in public by the members of the same sex is a part of their culture. In other words, what is valued and therefore appropriate in one culture may be inappropriate -- or even taboo -- in another.

For this reason, to avoid misunderstandings such as the one above or to understand the logic behind cultural patterns, studying American values gains importance in an ESL classroom. Our students should understand why people act this way or that way instead of judging them from their native cultural framework.

The values discussed below - individualism, equality, materialism, competition, informality, and directness and assertiveness - are often highlighted in American culture textbooks (Althen, 1988; Datesman, et al., 1997; Jason and Posner, 1995; Levine and Adelman, 1993). People who grow up in this culture share these values, but that does not mean that they all share exactly the same values. It only means that most of them agree with each other about what is wrong and what is right. However, values do not explain all behaviors. They greatly affect these behaviors, but other factors such as personality, age, gender, experiences, and economic and educational backgrounds also play a role in 
determining attitudes and behaviors. The value that is commonly given the most prominence is "individualism," and it, in turn, forms the basis for most of the other values (Althen, 1988; Datesman, et al., 1997; Jason and Posner, 1995; Levine and Adelman, 1993). Each value will be discussed below in terms of its basis and its possible misinterpretation by non-Americans.

\subsubsection{Individualism}

When the earliest settlers came to North America, they were looking for the freedom that they did not have in their countries because of "the controls placed on their lives by kings, governments, priests and churches, noblemen and aristocrats" which existed in European societies (Datesman, et al., 1997, p. 23). The main focus was on the individual, and the new continent created a climate of freedom by eliminating aristocracy and by later limiting the power of both the government and the churches. The concept of individual freedom or individualism emerged, and it is still the basis of most American values.

By individualism, Americans "consider themselves as separate individuals who are responsible for their own situations in life and their own destinies" (Althen, 1988, p. 4). This value can be observed even at very young ages. In the U.S., young children are given opportunities to make their own decisions. Even at a very early age, they can choose what they want to wear or where they want to go to eat. The parents' goal in raising their children becomes to rear a responsible and self-reliant person who will be able to move out one day to live by him- or herself.

The following personal experience illustrates a Turkish camp counselor's confusion due to a conflict between her values and American values. Since the families 
in Turkey support their children until they graduate from college, the families pay everything, including their children's personal expenses. It was very natural for her in a friendly conversation to say to her friends that her parents pay her telephone bills. The other American teens misinterpreted the whole situation, and they began to call her the "Turkish Princess" and assumed that she came from a high upper-class family. On the other hand, she considered the American parents cruel and selfish since they sent their children to work at a summer camp to make money to spend in the coming school semester although they were mostly from upper middle class families. She had a hard time understanding this situation and later explained to her friends how the two value systems were different from each other since "Americans are trained to conceive of themselves as separate individuals, and they assume everyone in the world is too" (Althen, 1988, p. 5). Accordingly, when Americans meet a foreigner coming from a tightly interdependent family culture, they assume that the foreigner is overly dependent on his or her family. In the same way, international students are open to misinterpret the "individualism" in American culture. The students who come from a culture with an interdependent family structure as a cultural feature consider leaving the house at the age of 18 or putting elderly parents in a nursing home to be self-centered and selfish.

The other notion that goes with individualism is Americans' attitude toward "privacy." A good example is the effort of an American family to give each of their children a separate room if they can afford it. "Having one's own bedroom, even as an infant, inculcates in a person the notion that she is entitled to a place of her own where she can be by herself and -- notice --keep her possessions" (Althen, 1988, p. 8). They strive to provide their children with all the possessions they want or need such as toys, 
books or furniture. Thus, Americans value privacy and feel the need for some time to themselves, while most foreigners "want to be with another person" or "dislike being alone" (Althen, 1988, p. 8).

This need for privacy may not be readily understood because of evidence to the contrary. For example, American yards can be unfenced and open to everyone. Curtains in houses can be open when a family is having its meals. People on the street may say "hi" to each other although they do not know each other. Nevertheless, Americans value their privacy very much, and this fact may create problems for newcomers. Americans have certain boundaries in their minds that should not be crossed (e.g., a definition of what constitutes privacy), and it is important for foreign students to understand these boundaries for the sake of their healthy socialization.

An example that reveals the students' confusion about privacy is the teacherstudent relationship in the U.S. American professors establish friendly relationships with their students as compared to more formal professor-student relationships in authoritybased school systems (Levine and Adelman, 1993, p. 211). Most professors' offices are open to any student who has questions and problems with their classwork. However, a foreign student may misinterpret the friendly relationship, and he or she may go to the professor's office and sit there for one or two hours. Besides informality, this situation raises another issue about the professor's privacy and the students' limitations. The student may have difficulty adjusting to the different roles of the professor or he or she may expect a different treatment from the professor due to their close relationship. This expectation may upset the professor since he or she would treat each student equally. 
These examples illustrate how the importance of individualism and privacy for Americans is demonstrated in- and outside of the home.

\subsubsection{Equality}

Americans believe that "all men are created equal" and "any person's opinion is as valid and worthy of attention as any other person's opinion" although they sometimes conflict with this value especially in racial relations (Althen, 1988, p. 8). They also assume that women are created equal and deserve the same level of respect as men do even though they often violate this value, too, in practice.

The concept of equality also represents the idea that each person should have an equal chance for success. Americans believe life is a race to win, and everybody must have the same chance to enter this race regardless of his or her family backgrounds. "Although Americans have modified their understanding of equality during their history and have blatantly violated it as well, the value remains a pervasive cultural norm" (Stewart, 1985, p. 51). Inequality among minority groups such as blacks or immigrants can sometimes be observed in practice as in job applications. However, "the American tendency is to minimize status differences rather than to emphasize them," and the U.S. is one of the countries in which people feel equal and have the same opportunities with everyone else to achieve (Levine and Adelman, 1993, p. 15).

Foreigners in the U.S. sometimes have problems understanding the concept of equality especially if they come from a society based on a caste system or social hierarchy. For example, in some countries, the roles are so fixed that sometimes a customer barely exchanges words with a waiter. The relationship is quite distant, and the waiter assumes that whoever gives the order at that point is superior to him. Therefore, 
some foreigners in the U.S. sometimes feel that they "are insulted by the way they are treated by service personnel (such as waiters in restaurants, clerks in stores, taxi drivers, etc.) " (Jason and Posner, 1995, p. 7). As another striking example, store clerks or waiters may introduce themselves by their first names and treat customers in an informal manner. Althen explains this attitude as "Americans have been trained to believe that they are as valuable as any other people, even if they happen to be engaged at a given time in an occupation that others might consider lowly" $(1988$, p. 10). But this is not to mean that Americans do not make any social distinctions according to sex, age, or wealth. They show the distinction in different ways such as tone of voice or choice of words in a conversation or simply seating arrangements at a party. Therefore, foreigners' perception of Americans being disrespectful of other people is a misconception.

Other manifestations of equality are also potentially confusing for foreigners, for example, equality as seen within the American family structure. In most countries, the father is still the decision-maker and consequently, the dominant figure. However, the mother and father in an American family may share the responsibility of making decisions and implementing them. This cultural difference in the family structure becomes an issue to clarify for foreign students.

In summary, Americans believe that -- no matter what a person's initial position in life -- any person has the opportunity to achieve in life. Based on this belief in equality, Americans, therefore, tend to minimize status differences rather than to emphasize them. 


\subsubsection{Materialism}

Materialism is the act of acquiring possessions and is the American value which is the most criticized by some foreigners who "consider Americans much more materialistic than Americans are likely to consider themselves" (Jason and Posner, 1995, p. 11).

In fact, Americans accept materialism as natural. They have been taught to work hard, to achieve, and to get as much as they can. They see the possessions as the natural benefits of their hard work as Stewart (1985) says, “Americans consider it almost a right to be materially well off and physically comfortable" (p. 64). The other reason that Americans acquire so many possessions is their appreciation of newness and innovation. They believe that new is better, so looking for a better product or purchasing an unnecessary item while they are shopping for another thing is not unusual. In fact there is a joke that "you go shopping for a shirt and buy a new dryer" due to the appeal of new products. Of

course, this excessive consumerism cannot be overgeneralized to apply to every American in the country. This culture also has people who are careful about their money.

One American practice which can be interpreted as based on materialism is the phenomena of commuter families and househusbands. Instances in which couples choose to live apart or in which the husband chooses to stay at home if the wife is making a good salary may be viewed by foreigners as manifestations of Americans' materialism. That is, Americans are seen as being more concerned with making money than with maintaining a unified family. However, a non-American may simply not be aware of some other contributing factors such as expensive living conditions or a competitive job environment in the U.S. 
In summary, it is true that Americans believe in working hard, achieving a lot, and finally getting more material possessions. While some foreigners would generalize the statement that "Americans are materialistic," to "Americans are greedy," the value of materialism should not be confused with greed, which would change the idea behind this value.

\subsubsection{Competition}

Most Americans believe that competition "brings out the best in any individual. They assert that it challenges or forces each person to produce the very best that is humanly possible" (Jason and Posner, 1995, p. 8). The foreign students who come from a society in which they are accustomed to cooperation rather than competition may find American classrooms uncomfortable. For example, Americans disrespect cheating on an exam or showing their exam papers and grades to their peers due to competition when “an individual's grades are calculated in relation to other's scores" (Levine and Adelman, 1993, p. 214). A need for a high grade-point average to get into a graduate school or to face a competitive job market after graduation are other reasons that students are individualistic and competitive.

In many other cultures, people commit themselves wholeheartedly to a group. However, Americans "pursue their own goals while cooperating with others who, likewise pursue their own" (Stewart, 1985, p. 56). They accept the group's expectations, too, but they feel free to leave the group if their expectations are not fulfilled in that group. Although Americans are becoming more group-oriented, they still show their individualism in every aspect of life, which leads into competition. Competition in a new educational system frustrates some foreign students. Therefore, ESL students who are 
informed about competition and individualism as American values can be aware of these values in an American classroom in order not to be distressed or disappointed later by their classmates' less-than-cooperative behaviors.

In sum, Americans are quite competitive in every aspect of their lives such as their education or career lives. To achieve their best in any area, they work hard and compete with each other and with themselves to bring out their best.

\subsubsection{Informality}

Althen explains the logic behind the American value "informality" as being based upon the concept that "notions of equality lead Americans to be quite informal in their general behavior and in their relationships with other people" (1988, p. 9). As an example of this informality, clothing will be the most noticeable one. "One can go to a symphony performance, for example, in any large American city nowadays and find some people in the audience dressed in blue jeans and tieless, short-sleeved shirts" (Jason and Posner, 1995, p. 10). Another example is in colleges where international students are shocked to see the students slouching down in chairs during class or hearing some American students calling their professors by their first names. This is "particularly striking with the Japanese, who cannot communicate until they know the status of the other person" (Stewart, 1985, p. 53).

In addition, students should not be confused about professors' role-switching. A professor can be very friendly and informal to his or her students outside of the classroom, but he or she is still the professor conducting and controlling the class. The professor may have several roles such as a facilitator in class and a friend out of the class. Students must realize when a professor changes his or her role, and they should 
understand that a professor's informality does not necessarily mean that he or she does not deserve any expected respect (Levine and Adelman, 1993, p. 211).

In summary, although Americans reflect informality in many areas such as schools or offices, they still have certain fixed roles which reflect formality according to the situational context. Learning how Americans switch their roles or how informality functions in this culture will help ESL students adapt themselves to these changes.

\subsubsection{Directness and Assertiveness}

Americans tend to be direct, open, and honest in their relations with other people. They assume that disagreements should be discussed among the people involved as in Stewart's saying,

"when faced with a problem, Americans like to get to its source. This means facing the facts, meeting the problem head on, putting the cards on the table and getting information 'straight from the horse's mouth.' It is also desirable to face people directly, to confront them intentionally" (1985, p. 52).

Another word, "assertive," is introduced "to describe the person who plainly and directly expresses feelings and requests" in a disagreement (Althen, 1988, p. 17). However, in some other cultures, people may prefer to be silent in this kind of situation, especially due to age, sex, and status differences.

The values discussed above form the backbone of American culture that most Americans share, and these values determine how Americans think and behave in their every-day lives. As Althen explains it, "A culture can be viewed as a collection of values and assumptions that go together to shape the way a group of people perceive and relate to the world around them" (1988, p. 4). Nevertheless, finding some Americans who do 
not agree with these American values and who challenge them is possible. However, these values underlie all domains of American culture. By focusing on three specific cultural domains, i.e., family, gender roles, and education, it is possible to explore the specific ways in which these values are manifested.

\subsection{Three Cultural Domains}

The cultural domains of family, gender roles, and education are chosen for the questionnaire developed as a part of this study because family shapes society, gender roles determine the attitude of each sex, and education is the most common reason for foreigners to have a prolonged stay in a foreign country. Although the domains are limited here to three, the questionnaire can be modified to reflect to other cultural domains. In the following section, each domain will be discussed within its relationship to the determining American values.

\subsubsection{Family}

How people satisfy their needs in a family differs from one culture to another. The way to handle a family problem or to rear a newborn in an American family is different from in a Japanese family because of their different value systems. For example, the first family will give quite a big amount of independence to their children in order to rear a responsible individual; the latter will expect the child to be dependent on the family to preserve their traditions. Americans expect their children to be independent due to the appreciation of "individualism" in their culture, while Japanese expect their children to be dependent on their family members. Japanese culture expects individuals to sacrifice their needs to those of the group due to their appreciation of "group 
orientation" (Althen, 1988; Datesman et al., 1997; Jason and Posner, 1995; Levine and Adelman, 1993).

Acculturation in a family, as Levine and Adelman (1993) emphasize, begins at birth by "the process of teaching new generations of children the customs and values of the parents' culture" (p. 172). In the U.S., if the parents can afford it, they prefer to separate themselves from their children physically soon after their birth. They want to preserve both their own and their children's "privacy." In addition, children's learning to be responsible for their possessions in their own room is the first step of their acquisition of American values such as "individualism," "privacy" and "materialism." In this way, responsibility can be seen as linked to a value such as "individualism" although the notion of responsibility is not specifically cited as an American value.

Another manifestation of "individualism" also starts at an early age by letting young children make their own decisions and be responsible for themselves (Althen, 1988, p. 4). Children learn to make decisions or take responsibility when they mow the neighbor's grass or baby-sit for other young children. They also earn "spending money" in these part-time jobs. In addition to their "individualism," children learn the value of money as well as the value of responsibility and hard work, all elements that contribute to one's ability to be independent. However, working at a part-time job at a young age and belonging to a middle-class family do not match in some cultures where working is shameful for a young adult if the father can support the family. For example, there is societal pressure in Turkey that does not let these teenagers have part-time jobs (although most of them are willing to) since other people such as neighbors or relatives will think that the father is stingy or cannot fulfill his fatherhood duties. 
In contrast to many cultures, in the U.S. young adults at about the age of eighteen are allowed or encouraged to move out and to live responsibly by themselves (Althen, 1988, p. 51). However, this expectation may not always be fulfilled in every family due to financial difficulties. Still, the parents expect their children to begin to contribute to their own support at an early age compared to most families in other cultures. For example, "Vietnamese children are trained to rely on their families, to honor the elderly people, and to fear foreigners" (Oxford, 1995, p. 104). Americans, on the other hand, encourage their children not to be "tied to their mothers' apron strings."

According to Levine and Adelman (1993), another issue that differs from other cultures, especially Asian and Arabic cultures, is choosing a partner to marry (p. 176). Young American adults choose their future partners, with whom they are often romantically involved without family guidance as an outcome of their "individualism." Even "sometimes children do precisely the opposite of what their parents wish in order to assert their independence" (Levine and Adelman, 1993, p. 176). Most of them marry the one they choose after dating. Through my observation this issue becomes a problem in some families where the parents immigrate to the U.S., but their children have grown up in this country. The way the parents see and solve the problem of choosing a life-time partner is different from that of the next generation. While the traditional immigrant parents may disapprove of dating and want to choose their child's spouse, the Americanized young adults prefer the customs that they observe in this new culture. Moreover, young adults want to show their "individualism" and "privacy" in their decision-making. However, these traditional families expect their children to obey the family decisions as an outcome of their emphasis on customs and beliefs from the past. 
Individualism is also seen to be related to American decisions concerning the elderly. For instance, when the students who come from a traditional interdependent family background see that Americans put their elderly relatives in retirement homes, they cannot understand and accept it. However, Levine and Adelman (1993) state that the treatment of elderly people in the U.S. also reflects the values of "individualism" and "privacy" (p. 176). Their financial support is mostly provided by social security or welfare systems, which decreases their dependency on their children. In addition, some elderly people may prefer to stay in a nursing or retirement home since they "often seek their own friends rather than becoming too emotionally dependent on their children" (Levine and Adelman, 1993, p. 176). Children may finance their parents' stay in a retirement home, but they will prefer not to live together to allow both sides independence just as their parents encouraged them to be independent at a very young age. The same spirit of independence that guides child raising affects elderly people. Children may also prefer the nursing houses for their parents since these places offer medical care for people with physical disabilities or illness.

The interpretation of another issue that differs from one culture to another is "divorce." It is estimated that "almost 50 percent of marriages in the U.S. end in divorce" (Levine and Adelman, 1993, p. 181). Changes in the American family structure such as the emergence of more working mothers have resulted in high rates of separation. As an outcome of "equality," American women get divorced at higher rates while women in other cultures may not choose divorce due to economic conditions and traditions. On the other hand, single-parent families in the U.S. are mostly headed by women and many of them do not receive alimony or child support payments. In fact, 
single mothers as well as single fathers "often feel 'stretched to their limits' with the unending responsibilities that face them" (p. 181). On the other hand, in spite of the high divorce rate and the burden of supporting a family after the divorce, marriage is still important for most Americans. "The remarriage rate remains high, with approximately four out of five divorced couples eventually remarrying other people" (Levine and Adelman, 1993, p. 182). People still believe in the marriage institution, and they want to try again with another partner. These new families are called "blended families" or "stepfamilies" which are composed of previously-married adults and the children of their previous marriages. Some foreigners have misconceptions about American culture such as a decline in moral values in the American family due to the high divorce rate.

However, the family institution is not dying, but different family types are inevitable in a rapidly changing society.

In this section, the analysis of the cultural domain of the family has shown that the American values of individualism, privacy, and materialism underlie many common family practices such as choosing a partner to marry and having a part-time job at a young age. Through these practices, American children learn these basic values. It is also clear that cultural values are not discrete. That is, one family practice may be based on a number of values.

\subsubsection{Gender Roles}

In traditional societies such as in Arabic culture, the gender roles are quite strictly defined by the members of the community. If one were to ask the duties of a good wife to a randomly chosen group of Arabic men, their list will be almost the same (Althen, 1988, p. 87). They will say "the wife should be a virgin at the time of her marriage, that 
she should obey her husband and her mother-in-law, and that she should be devoted to raising her children" (p. 87). However, if the same question were asked to a group of Americans, the answers would likely vary. While it is hard to generalize a pattern of gender roles in American culture, a few facts as explained below may enlighten foreigners and change their stereotypes about both American women and men.

One common stereotype for American women is that they are domineering. Some foreigners believe that they rule the men. Correspondingly, they think that American men are weak by letting women dominate them. For example, in some cultures people believe that changing diapers or preparing meals is absolutely a woman's duty. They believe that for a man to share responsibilities with a wife will weaken his masculinity. Of course, it is possible to find examples in which an American woman dominates her husband fitting these stereotypes, but living quite a while in the U.S. will eventually reveal the fact that this is "an overgeneralized notion that applied in some cases but not in all" (Althen, 1988, p. 89).

In the 1960s, women in the U.S. started to use the term "women's liberation" to aim to end the discrimination against women in places such as the home or workplace. The themes underlying this movement "are the same themes -- individualism, independence, and equality -- that underlie American society in general" (Althen, 1988, p. 90).

"Traditionally, the male was responsible for the financial support of the home and the family members, and the female was responsible for emotional support, child raising, and housekeeping. However, during the past two to three decades in the United States, gender roles have 
been redefined, with an increasing number of mothers in the work force"

(Levine and Adelman, 1993, p. 179).

The more American women began to participate in the labor force, the more they asserted their independence. Men began to share the household responsibilities such as cooking or changing the diapers, which were done by only women for many decades before. However, still

"most women today struggle to balance the traditional expectations of the past and the new demands and visions of the present. They also straddle two worlds -- the private domain of home and family and the public domain of the work. The resulting pressure to be 'super-Mom' remains a concern, for wives are commonly the primary caretakers for children and home, even when their jobs are as demanding as those of their husbands" (Jason and Posner, 1995, p. 133).

On the other hand, compared to other cultures where the man is the dominant figure, it can be safely said that there is a more equitable sharing of family and home responsibilities in an American family.

Growing out of the push for gender equity, new terms and new roles began to appear such as "househusbands," "commuter couples," and "blended families." The man began to stay at home to take care of the house and children if it was necessary and if the wife was making a good salary. The lack of employment opportunities and difficult economic conditions lead to another term called "commuter couples" in which the wife and husband work and live in different geographical locations and see each other on weekends or less often. Some commuter couples believe that "their family life is better 
because they make the most of the little 'family time' that they have" (Levine and Adelman, 1993, p. 181).

Despite all the value changes which have occurred in the past 30 to 40 years in the U.S., there are still many individuals and communities who support the traditional patterns, especially woman's role in society and in the home. It is also necessary to mention that the regional, ethnic, and religious heterogeneity in this country means that people will have different ideas about gender roles. Although this heterogeneity makes it harder to define gender roles in the U.S., American women "are now freer to define themselves and their place in society" (Jason and Posner, 1995, p. 133).

In summary, the American values that underlie the emergence of new gender roles in the U.S. are individualism and equality. As a result of these changing roles, both men and women have begun to choose new family structures, such as commuter couples, in order to fulfill their individual and collective needs more equitably.

\subsubsection{Education}

Many newcomers to the U.S. are here as foreign students. As with any other cultural institution, educational systems are different from one country to another because of different value systems, historical models, and national needs. As a result, the classroom can be the scene of potential cross-cultural misunderstanding.

Many foreign students believe that "American post-secondary educational institutions have rather low admissions standards" compared to their countries (Althen, 1988. P. 53). However, the students from all over the world dream about coming to the U.S. to further their education. Easy admission may be misunderstood by foreigners since the American educational system is based on "the idea that as many people as 
possible should have access to as much education as possible" (Althen, 1988, p. 54).

This idea again comes from the American value of "equality." In contrast, these students come from more elitist systems of education in which only the brightest students are permitted to continue their studies beyond the secondary school level.

Another value, "individualism," is strongly observed in the American classroom. For example, a student's participation is expected in most classes. These classes are designed around discussions, presentations, and group activities. The idea underlying this application is the expectation of the students' individualism in which they should present their own ideas and identities to others in the class. This application may create confusion for some foreign students who are accustomed to a system in which students must obey their professors and be passive in class. They may especially have difficulty accepting the fact that they can challenge their professor's ideas, and that they should be able to defend their own opinions as well (Althen, 1988, pp. 3-4)

As Levine and Adelman (1993) state, many professors are of the opinion that students should be responsible for their own learning. If an assignment is given to students, these students are responsible for completing it, whether their professor later checks it or not. Professors expect their students to come to class in order to learn, not just to get a high grade and pass. However, in some other countries, some students make a bargain with their teachers about their low grades, which is not an appropriate behavior in the American school system. In an American classroom, if students disagree with the grade, they "may approach their professor with their objection and ask for a change in the grade" without expressing their anger (p. 215). 
Most American classrooms are informal and threat-free unlike classes in many other countries. In many other cultures, teachers are very distant from their students and unwilling to have a good rapport with their students in order to preserve their authority. For example, the researcher has learned from her students that students are still beaten with a wooden stick when they make a mistake in some Asian countries.

On the other hand, the fact that an American professor is informal does not necessarily mean that he or she is not well respected or that he or she does not do the job properly. In contrast, these professors believe that a "relaxed classroom environment is conducive to learning and innovation" (Levine and Adelman, 1993, p. 210). Moreover, professors can improve their relationships with their students outside of the classroom, too. The American value, "informality," in fact provides a friendly and a nonthreatening classroom environment where they can ask their questions or challenge their professors. "Graduate students typically have more intense relationships with their professors than undergraduates do; at smaller schools student-teacher relationships are typically even less formal than they are at larger schools" (Althen, 1988, p. 129). The professors may go out for a cup of coffee with their students. However, it does not mean that their students will be treated differently or the students will not have to study enough for their classes.

Another value, which is highly expected in an American classroom, is "honesty." Students should not cheat or cooperate with each other during a class or take-home exam. American students also do not prefer to discuss their grades with their peers unlike what some foreign students would do. Most foreign students get offended when their peers prefer not to cooperate, but compete with each other. They take it personally although 
they forget the fact that Americans need to achieve high grades to enter graduate schools or face a competitive job market.

Once again, the value of individualism is emphasized in the American educational system as in the domains of the family and gender roles. Other values -- equality, informality, and competition -- also underscore the structure of American education. Having an awareness of these cultural values becomes an important factor in enhancing a successful educational life for international students in the U.S.

In Chapter Three, the researcher has examined a set of American values and has explored how these identified values are apparent in several cultural domains. From this examination, it is clear that cultural values are interrelated. For example, the cited authors have identified "individualism" as an important American value. However, this value is intricately related to other values such as privacy, equality, responsibility, and independence. As a result, cultural practices similarly reflect a combination of values. In the development of the cultural needs questionnaire, an attempt is made to identify the family, gender role, and educational practices in which these values are manifested so as to ultimately determine the second language learner's awareness of these American values. 


\section{CHAPTER FOUR}

\section{DEVELOPING AND PILOTING THE QUESTIONNAIRE}

\subsection{Developing the Questionnaire}

After analyzing the domains of family, gender roles, and education within the context of their underlying American values, the questionnaire was developed. In the proposed questionnaire, each question reflects one of the American values identified earlier. In this chapter, the proposed questions and piloting of the questionnaire will be discussed. The proposed questions will be explored from the perspectives of the aim of the questions and the values that they reflect. In the following section, the results and effectiveness of the questionnaire will be discussed. The questionnaire includes three types of questions: questions designed to gather demographic information, questions designed to provide insights into the students' own culture, and questions designed to evaluate the students' awareness of American culture. Each group of questions is discussed in turn. The entire questionnaire is given in Appendix A.

\subsubsection{Demographic Questions}

The demographic questions -- nationality, age, gender, educational background, length of stay, living with an American roommate, participating in American facilities, usefulness of American Culture courses, cultural misunderstandings, understanding the American concepts, and the similarity between host culture and native culture -- were designed to provide a profile of the students involved in the study, and to offer a means of analyzing the answers to the non-demographic questions. For example, question three -gender -- aims to make sure that female students answer the questions specially designed

for their gender and vice versa. Also, it provides a basis for measuring whether different 
gender groups answer the questions related to gender roles (questions 17, 20, 24, 25) differently.

In the questionnaire, question four -- educational background -- aims to determine the students' educational background. The questions from five to seven aim to measure the extent to which the students are able to observe and/or live in American culture. Questions eight and nine aim to determine the students' opinions about American Culture courses. Question 10 -- cultural misunderstandings -- is designed to determine if the students are aware of any misunderstandings which have happened to them in American culture. Question 11 -- understanding the American concepts -- aims to rank how much the students understand the topics of American culture and, consequently, to find out how much the American culture and their native culture are similar in the students' opinion.

In summary, the demographic questions are designed to gather general demographic and background information about the students.

\subsubsection{Native Culture Questions}

Although this questionnaire is designed to measure the students' awareness of American culture, the questions about their own cultures will give feedback to the ESL teacher to determine whether or not the students have comparable values in their own cultures. These questions reflect two assumptions: first, teaching culture can be more effective when learners have a raised awareness of their own cultures, and second, that the more the teacher knows about the students' cultural perspectives on a given cultural issue, the greater the likelihood of facilitating cross-cultural awareness and understanding in the classroom. 


\subsubsection{Individualism}

In this and the subsequent section, the questions will be grouped according to the underlying values. In addition, each question is given an identifying title. Two questions concern individualism: "becoming independent" and "family unit." Question 13 -becoming independent -- aims to compare and contrast the age that the students leave home in their native cultures. Question 16 -- family unit -- aims to determine the students' cultural practices concerning elderly people, that is, whether or not older relatives remain with the family.

\subsubsection{Equality}

The value of equality is reflected in the issues of family authority, divorce, and marriage. Question 17 -- father's word -- identifies who is the dominant figure in a family in the students' culture. Question 19 -- divorce -- aims to compare the students' native culture to American culture on divorce and to determine if the two cultures are similar or different with respect to certain reasons for getting divorced. Finally, question 22 -- marriage age -- aims to trace the expectations in the students' culture about permission to marry.

\subsubsection{Competition}

The value of competition is examined as it relates to education. Question 37 -cheating on an exam -- and question 38 -- answering a question in class -- aim to measure the degree of competitiveness in the classroom. The questions can determine whether the students' cultures value cooperation over competition or vice versa. 


\subsubsection{Informality}

Informality is measured within the issues of "meeting a young woman" and "physical contact with the other sex in public." Question 26 -- meeting a young woman -- and question 27 -- physical contact with the other sex in public -- are designed to examine what the students would do in these given scenarios; that is, will their behaviors reflect a more formal or informal attitude in interactions with members of the opposite sex? It is believed that the answers will reveal their cultural attitude about gender roles and informality.

\subsubsection{Directness and Assertiveness}

The value of directness and assertiveness are manifested in many cultural domains. Here these values are examined in the educational domain. Question 35 -- eye contact -- aims to determine the students' directness toward solving their problems. Eye contact in any circumstances is very important in American culture. However, a foreign student may avoid eye contact with another person especially when this student has a problem.

The above questions are designed to measure the students' own cultural backgrounds as a comparison and contrast to the American values. Although the purpose of the questionnaire is to analyze the students' awareness of American culture, their responses to the questions may help the ESL teacher determine the students' potential misinterpretations of American culture. By the same token, the American culture questions which will be discussed below will give feedback concerning the students' awareness of these American values as seen in the domains of family, gender roles, and education. 


\subsubsection{American Culture Questions}

This section outlines the questions related specifically to students' awareness of American culture. The questions are designed to determine student reaction to American practices and behaviors. While each question is related to one or more American values, it must be noted that a student's awareness of a particular practice does not necessarily include an understanding of the underlying value. The researcher returns to this issue below.

\subsubsection{Individualism}

The value of individualism is learned in the family and is demonstrated in several practices related to the family. Question 14 -- leaving the house at the age of 18 -- aims to measure the students' reactions to Americans' taking responsibility and leaving their family home at a young age. Several choices are given to determine the students' interpretation of this practice. Question 15 -- nursing homes -- aims to trace the students' reactions to putting elderly family members into a retirement home. Finally, question 21 -- teens' part-time work -- aims to learn the students' opinions about American teens' working and taking responsibility at a young age.

\subsubsection{Equality}

Equality of individuals may be a difficult value for non-Americans to understand as it is manifested in American families and educational institutions. To begin, question 18 -- divorce -- aims to bring out the students' potential stereotypes of the American family. They may interpret the American's high divorce rate as an outcome of women's liberation. 
Another family practice, that of blended families, is examined in Question 20C. The question is designed to determine the students' attitude toward this new concept. Although this new concept is not totally an outcome of equality, we can still consider that the possibility of a woman's getting remarried after a divorce in this country is higher compared to other cultures in which divorced women's social status and roles are changed after their divorce due to social pressure.

The other manifestation of equality is reflected in the issues of American education. Question 31 -- getting into an American college -- explores the students' impressions of the American educational system and their difficulties in this new system. Although the American college system aims to give everyone an equal opportunity to education, some foreign students misinterpret this equality as easiness in getting into an American college.

\subsubsection{Materialism}

The value of materialism is examined as it relates to family structure. Question $20 \mathrm{~A}$-- househusbands -- aims to measure the students' reaction to this new concept which can be seen as a manifestation of materialism. Question 20B -- commuter couples -- aims to determine the students' attitude toward commuter couples. In both examples, foreign students may think that the wife as sole wage-earner or two wage-earners living apart while being married are simply the results of a desire for more money. These

questions also address the issue of equality in that the wife's role in the family is seen as equal to that of the husband's. 


\subsubsection{Informality}

Informality is manifested in the issues of education. Question 29 -- having a beer with the professors-- aims to determine the students' reaction to the American professors' informality as seen in informal social relations with students. Question 34 -- social relationships with professors -- aims to further determine the students' evaluation of this particular behavior as a manifestation of this American informality. In the first example, the student's evaluation of this informal relationship and in the second example, their particular role in this informal relationship are asked.

\subsubsection{Directness and Assertiveness}

Two questions concern directness and assertiveness: "bridal registry" and “criticizing the teachers." Question 23 -- bridal registry -- aims to learn the students' opinion about this American custom. Some foreign students may interpret this American behavior as being very direct as asking what kind of a gift the guests could bring may be rude in their culture. Question 33 -- criticizing teachers -- aims to measure the relationship between teachers and students. Criticizing a teacher in a lecture can be too direct for a foreign student who comes from a teacher-dominant educational background. In both American behaviors, the students may conclude that Americans are very direct in what they want and what they expect.

The questions developed for this questionnaire reflect a broad range of American values. Although some questions can be seen to include more than one value, the questions have been classified based on the most prominent value underlying the question. Some people may argue the validity of these values and their manifestations. However, these questions result from an analysis of scholarship on culture, American 
culture textbooks, and the researcher's own experience both as a student and as an ESL

teacher in the U.S. (Althen, 1988; Datesman et al., 1997; Jason and Posner, 1995; Levine and Adelman, 1993).

\subsection{Piloting the Questionnaire}

In this section, the results and effectiveness of the questionnaire will be discussed. The section is divided into four parts:

1. a description of the methodology,

2. a report and discussion of the background information,

3. a report and discussion of the native culture questions, and

4. a report and an analysis of the results concerning American Culture.

\subsubsection{Methodology}

The questionnaire was given to 19 non-native ESL students who were students in the Intensive English Program at West Virginia University. The questionnaire was administered in one class and took approximately one and a half hours to complete. The students were instructed by the researcher to leave the questions blank if they wanted to, and they were encouraged to ask the meaning of any unknown vocabulary. The students were allowed to leave when they had finished.

\subsubsection{Results}

\subsubsection{Background Information}

The first page of the questionnaire -- questions 1 through 10 -- asked about the students' background. The group consisted of twelve male and seven female students. They were from Belgium, Brazil, China, Colombia, Egypt, Japan, Kuwait, Saudi Arabia, and Venezuela. Fourteen students were in the age range between 18 and 25. Five 
students were between 26 and 35. Four students were high-school graduates. Eleven students were university or college graduates. Four students had either Master's or Doctoral degrees.

In terms of their experience with American culture, only one student had been living in the U.S. for more than one year. Four students were living with American families or American roommates. The rest were either staying by themselves or with foreign roommates. Twelve students (or 63\%) either often or sometimes joined or participated in American organizations, social clubs or events. On the other hand, seven students (or 37\%) mentioned that they seldom or never participated in them. Only Arabic students mentioned that they did not enjoy learning about American culture by experiencing it. One of them mentioned that he only enjoyed experiencing the big events. Two students (or 11\%) mentioned that they never had an American Culture course. Most students claimed that they experienced cultural misunderstandings from time to time; however, three students (or 16\%) emphasized that they never faced any cultural misunderstanding. These results are summarized in tables 1 through 12 in Appendix B.

Questions 11 and 12 ask students to respond on a scale of 0 to 5 how well they understand American culture and how similar American culture is to their own cultures, as seen below.

11. In your opinion, how well do you understand each of the following attitudes, principles, or concepts of American Culture?

Rate the following 0 through $5 . \quad 0=$ not understood at all $5=$ very well understood $\begin{array}{lllllll}\text { American values } & 0 & 1 & 2 & 3 & 4 & 5\end{array}$ 


$\begin{array}{lllllll}\text { Politics } & 0 & 1 & 2 & 3 & 4 & 5 \\ \text { Family Life } & 0 & 1 & 2 & 3 & 4 & 5 \\ \text { Education } & 0 & 1 & 2 & 3 & 4 & 5 \\ \text { Religion } & 0 & 1 & 2 & 3 & 4 & 5 \\ \text { Male-Female Relationships } & 0 & 1 & 2 & 3 & 4 & 5 \\ \text { Personal Cleanliness } & 0 & 1 & 2 & 3 & 4 & 5 \\ \text { Behavior in Public Places } & 0 & 1 & 2 & 3 & 4 & 5 \\ \text { Business } & 0 & 1 & 2 & 3 & 4 & 5 \\ \text { Nonverbal Communication } & 0 & 1 & 2 & 3 & 4 & 5\end{array}$

12. How similar are the expectations of your own culture to those of the American Culture?

Rate the following 0 through 5. $0=$ not similar at all $5=$ almost identical

$\begin{array}{lllllll}\text { American values } & 0 & 1 & 2 & 3 & 4 & 5 \\ \text { Politics } & 0 & 1 & 2 & 3 & 4 & 5 \\ \text { Family Life } & 0 & 1 & 2 & 3 & 4 & 5 \\ \text { Education } & 0 & 1 & 2 & 3 & 4 & 5 \\ \text { Religion } & 0 & 1 & 2 & 3 & 4 & 5 \\ \text { Male-Female Relationships } & 0 & 1 & 2 & 3 & 4 & 5 \\ \text { Personal Cleanliness } & 0 & 1 & 2 & 3 & 4 & 5 \\ \text { Behavior in Public Places } & 0 & 1 & 2 & 3 & 4 & 5 \\ \text { Business } & 0 & 1 & 2 & 3 & 4 & 5 \\ \text { Nonverbal Communication } & 0 & 1 & 2 & 3 & 4 & 5\end{array}$


The responses concerning family life, education, and gender roles are given here. Six students (or 32\%) claimed that they do not understand family life in the U.S. while thirteen (or 68\%) of them claimed the opposite. Twelve students (or 63\%) found American family life different from their own. However, five students (or 26\%) found it similar to theirs. Two of them (or 11\%) even found it identical to their own family lives. In terms of education, only two students (or 11\%) showed their struggles to understand the education system in the U.S. whereas seventeen students (or 89\%) responded that they understood American education well. Seven students (or 37\%) responded that education in the U.S. was not similar to the education in their countries although twelve students (or 63\%) did not find it very different. Regarding gender roles, two students (or $11 \%$ ) emphasized that they did not understand the male-female relationships in the U.S. Seventeen students (or 89\%) noted that they did not have problems understanding malefemale relationships in this culture. Eight students (or 42\%) found the male-female relationships different from theirs while eleven students (or 58\%) claimed that they were similar. The table showing the results of other concepts asked in questions 11 and 12 can be found in Appendix B.

\subsubsection{Discussion}

\subsubsection{Background Information}

In the background information section, although all of the questions helped the researcher determine the students' personal and educational backgrounds and their exposure to American Culture, some of the background questions should be altered, as outlined here. For example, in question 7 -- participating in American organizations -the choices "sometimes" could be omitted in order to get a clearer indication of the 
students" participation. "Often" and "seldom" would be substituted for "sometimes" since these two choices show frequency from both negative and positive perspectives whereas "sometimes" does not give such information.

Question 9 asks, "Is the American Culture course useful to you in adapting to life in the U.S.?" In this question, a new question "why?" should be added to understand the strengths and weaknesses of such a class. The information provided revealed that only ten students found the course useful while four of them thought the opposite. Two students mentioned that they never had an American Culture course before.

Similar to question 7 -- participating in American organizations --, in question 10 -- experiencing cultural misunderstandings -- the choices "sometimes" can be omitted in order to get more accurate information about the students' frequency of involvement in cultural misunderstandings.

Questions 11 and 12 -- how well they understand the American culture and how similar the expectations of their culture are to the American culture -- did not reveal any useful information. Analyzing the results was problematic due to the large extension of the scale, and the results did not give a clear picture of how well the students understood American culture and how similar their expectations were. Instead of dividing the measurement into six parts, it could be divided into four parts.

In addition to the issues noted above, there are several disadvantages of using questionnaires, such as a low response rate, which can negatively affect the validity of the data and the use of open-ended or ambiguous questions, which can produce inappropriate, incorrect, insufficient or overly abundant responses from the subjects. This research did in fact suffer from a low-questionnaire response and from the open- 
endedness of the questions on the questionnaire designed for purposes of this research. The responses obtained were too numerous and varied. We return to these issues in Chapter Five.

\subsection{Statistical Analysis}

In this research, we used the Chi-Square test $\left(\chi^{2}\right)$, specifically Fisher's exact test, to check for the consistency within the frequencies of the variables (i.e., the tallies).

Fisher's exact test, which is used with small samples, "does not rely on the $\chi^{2}$ distribution; rather exact probabilities are computed" (Shavelson, 1988, p. 457). The variables of age, gender, educational background, length of stay, American roommates, American activities, and American culture classes were analyzed in relation to the responses to the individual culture questions. Since no item demonstrated significance, no further statistical analysis was pursued.

\subsection{Concluding Remarks}

The researcher designed this study to check the usability and the reliability of the cultural needs questionnaire. The statistical analysis of the data revealed no significant findings. This is due to several factors; the number of subjects that participated in the present research were fewer than the desired number, i.e. at least 30 (Butler, 1985). In addition, the questionnaire should have focused on one of the variables affecting SLA, i.e., age, sex, educational level, and so on. With the focus on one variable, the others should have been kept constant to obtain more reliable results.

Overall, the students showed sincerity in answering the questionnaire and giving their opinions about American culture. However, in terms of consistency, students sometimes contradicted themselves in their responses to related questions. Even though 
the questionnaire results are not statistically significant, the students' answers show that some students seem to have begun to identify the validity of American behaviors. For example, in question 29 -- having a beer with professors --, a majority of the students (79\%) selected the choice "d" -- friendly -- which is consistent with the American value of "informality." It is impossible to claim, however, that they grasp the American values underlying the behaviors. This would tend to verify Hanvey's stages of cultural awareness in which students begin to recognize the validity of the target culture patterns - i.e., these students are moving from stage 2 to stage 3. Perhaps an additional intermediate stage is required; that is, a stage in which the learner sees the behavior as acceptable but does not yet understand the cultural values underlying that behavior.

In order to answer the question, "does the questionnaire show what their cultural needs are," it can be concluded that the questionnaire helped the researcher determine the cultural conflicts which could be discussed in the class. However, a subject pool of nineteen students is not adequate to gather enough data to insure accuracy although having students from many different cultures presents an opportunity to observe diverse cultures. In addition, the groups often showed inconsistency in their responses. The number of subjects makes it impossible to determine whether those inconsistencies reflect diverse personalities or reflect the subjects' changing cultural perspectives. However, these data can be tested with a larger subject pool in the future.

In conclusion, the pilot study of this cultural needs questionnaire revealed that there were some difficulties in the development of this instrument. Therefore, it is clear that the questionnaire did not provide the information expected. As a result, the focus of the project has shifted away from the original purpose -- the collection of cultural data -- 
and is now focused on the problems inherent in the instrument itself that rendered it ineffective. The re-design of the questionnaire will be discussed in the following chapter. 


\section{CHAPTER FIVE}

\section{CHARACTERISTICS AND VALIDITY OF AN EFFECTIVE SURVEY QUESTIONNAIRE}

In this section, the format of the modified questionnaire will be discussed, including the rationale supporting the revised model and the intended purpose of the original questionnaire. The original questionnaire was administrated to students in an intensive English program. However, the chi-squares run after the administration proved that there were no significant differences among the respondents on most of the items. This suggested that the questionnaire needed to be modified. The researcher began to investigate in greater depth how to design questionnaires, and, as a result, she modified the original questionnaire. Linda B. Bourque and Eve P. Fielder's book, How to Conduct Self-Administered and Mail Surveys (1995), provided the conceptual framework for the design of the revised questionnaire, including the selection of the administration format, demographic content, thematic focus, question items, instructions, and cover letter. Since the original instrument proved to be ineffective, the following discussion focuses on the characteristics that should have been present, and on the evaluation of the revised questionnaire.

\subsection{Self-administered Questionnaires: Selection of an Administration Format} Self-administered questionnaires are instruments "used to collect information from people who complete the instrument themselves" (Bourque \& Fielder, 1995, p. 2). There are two types of self-administered questionnaires, one in which people answer in the presence of the surveyor or other supervising personnel and the other type which is administered without the presence of these proctors. These two types are further 
categorized according to four conditions of administration: one-to-one, group, semisupervised, and unsupervised, which are determined as follows (Bourque \& Fielder, 1995, pp. 8-9):

One-to-one administration: the respondent is in a one-to-one situation with the surveyor. Thus, the surveyor is available to answer the respondent's questions or to clarify unfamiliar concepts. This approach maximizes confidentiality in face-to-face interviews; however, the disadvantage of this type is its high cost.

Group Administration: the questionnaires are distributed to the respondents in a classroom, a workplace, or a group setting. Respondents are expected to complete the questionnaire without consulting other people. However, depending on the purpose of the study, the administrator may answer and clarify any questions or deflect these questions. This format is efficient especially in pretesting although it is not usable with large populations.

Semisupervised Administration: as in group administrations, respondents receive the questionnaire in the same setting such as a baby clinic or registration line. They hear the same set of verbal instructions, and their questions are handled in a similar way. However, the instructions or clarifications should be limited in order to assure consistency across groups who might have different administrators. This approach is less expensive than some other models, but the researcher may end up with inconsistent instructions if the administrators do not follow the same instructions. Unsupervised Administration: these are questionnaires that are sent through the mail. Therefore, it is necessary that the questionnaire be self-sufficient due to the absence of an 
administrator. It is possible to get a wider distribution and more representative samples although there is no control over who responds to the questionnaire.

The surveyor in the administration of a questionnaire should choose one of these categories appropriate to the research purpose, in order to maximize collection of a complete, reliable, and valid data set. The next section gives a framework for the construction of an effective questionnaire.

\subsection{Questionnaire Construction: Characteristics of an Effective Instrument}

If the objective of the study is clear and not complex, a self-administered questionnaire can be used for the data collection, since the subjects should be able to understand the purpose of the study and the content of the questionnaire. In addition to making sure that the objective is clear, Bourque and Fielder (1995) suggest the following as characteristics of a good questionnaire.

1. A self-administered questionnaire must be short enough to conform to the time constraints placed upon the administration of the instrument. In most academic settings, this means that the time should be no more than a single class period. If the questionnaire must be short, then certainly the number of questions and the topic areas should be limited.

2. The questions on a self-administered questionnaire must be closed-ended ones, in which respondents select from among several prepared responses. Although very motivated subjects may be eager to answer open-ended questions, the majority prefers closed-ended questions. The other disadvantage that a surveyor may face in asking openended questions is that of not getting sufficient amounts of data from the respondents, due to the terseness or absence of responses. 
3. The questionnaire should be self-directed to the extent that a potential respondent could provide answers without the need for a supervisor to be present in the place of administration. Although an administrator can assist the group, the purpose here is to make the questionnaire as easy as possible for the respondent. The instructions should be clear and should give enough information to cover the respondents' potential questions or give sufficient information to lessen the confusion.

4. The questionnaire should not have "branches or skips" (p. 18). In this context, "branch" refers to a procedure through which succeeding items are sequenced on the basis of the response to the preceding question. Thus, for example, a "yes" response would lead the respondent to one question, while a "no" response would lead to a different question. Similarly, "skip" refers to a procedure in which the respondent must skip a question if the previous question leads him/her to do so. For example, an incident may not apply to a respondent. Then, the question asks the respondent to skip a coming question.

In addition to the suggested general characteristics of a questionnaire, Bourque and Fielder outline a set of data for the content items in the questionnaire. The next section gives an explanation of how to design these questionnaire items.

\subsubsection{Content of the Questionnaire}

\subsubsection{Demographic Questions}

The authors strongly recommend demographic questions in a questionnaire. They emphasize that not including demographic questions to save space and time or compressing all the questions into two pages to make the questionnaire look shorter may result in the failure to collect data that would be necessary to answer important questions 
about the sample population. Demographic data include personal information such as gender, marital status, and ethnic identification as well as other topics that might aid the researcher in grouping respondents by pre-determined categories. The decision about where to place the demographic questions in a questionnaire depends on the researcher's preference. However, Bourque and Fielder prefer to place the demographic questions at the end of the questionnaire. They recommend this for three reasons. First, assuming that a cover letter, which shows the purpose of the study and encourages the respondent to participate in the study, is attached to the questionnaire, then respondents could move directly to the substantive items. If demographic questions are placed at the beginning of the questionnaire, then the focus of the respondents tends to be shifted away from the purpose of the instrument. Second, most respondents find demographic questions boring, thus are likely to lose interest in the questionnaire before getting to the main items.

Finally, some respondents may find some questions such as age and income inappropriate, when they are not yet aware of the complete content of the questionnaire. By placing demographic questions at the end, students are familiar with their responses and may be more willing to reveal the information about themselves.

\subsubsection{Focus}

Besides the demographic questions, the research questions about the respondents' behaviors, experiences, status, thoughts, feelings, knowledge, attitudes, etc., form the main body of the questionnaire. Bourque and Fielder suggest that the topic must be contained; that is, the study should have a single objective (pp. 26-27). Accordingly, all the sections must interrelate to realize that objective. Further, focusing on present ideas, attitudes, and experiences in a questionnaire increases the respondents' willingness to 
complete it than does asking the respondents to reflect on past or future times.

Additionally, the surveyor should construct the questionnaire so that everyone answers every question. In other words, every question should be applicable to each respondent.

\subsection{Question items.}

Bourque and Fielder advise that "questions must be as short as possible and specific rather than general in what they reference" (1995, p. 42). Long, run-on sentences should be avoided. Besides being short, the questions should not be asking two things at once. Furthermore, the writers warn questionnaire designers to avoid vague qualifiers such as "usually." They believe that these qualifiers introduce a subjectivity into the question that makes it impossible to quantify the data, since what one person might consider as "usually" may well be what another would refer to as "sometimes." This, in turn, introduces a subjective component into the encoding of the data.

Being careful to minimize the use of abstract terms or jargon is also important according to Bourque and Fielder (1995, p. 47). They suggest that the surveyor should provide a definition if such a term must be used. They also advise the surveyors to order their questions so that they progress from the easier to the more complex or sensitive questions. In addition to easy-to-difficult progression, it is recommended that questions be organized in a logical order so that respondents do not sense a constant shifting between topics.

\subsection{Response items.}

According to Bourque and Fielder (1995), four issues must be considered in developing response categories. First, the response items should be exhaustive, yet not very long. If response items are too restrictive or too vague, respondents may become 
frustrated by the feeling of inability to express themselves, which will lower the participation rate.

Second, creating mutually exclusive answer categories lessens the respondents' possible frustration. In order to avoid ambiguity, the vocabulary choice or the wording of the alternatives is very important. For example, the researcher should be careful when the verb forms are used to express past or present such as the verb, "read."

Response categories should be made more flexible by making it possible for subjects to select more than one answer to describe themselves or by creating "a separate variable for each answer response provided and ... consistent codes for whether a given response is or is not selected or circled by the respondent" (p. 65). In this way, the respondent will be able to choose the appropriate one rather than leaving the question blank or choosing an irrelevant one.

Finally, residual "other" or "not applicable" can be used to increase flexibility in answer categories. However, this technique should be minimized by generating more possible answers, since the respondents tend to either put themselves into a category simply because it is there, or quit the questionnaire because of their frustration if the answers do not allow them to describe themselves accurately (p. 69).

\subsubsection{Instructions}

Bourque and Fielder maintain that it is important to include three kinds of instructions: general, transitional, and question-answering (p. 70). General instructions introduce the questionnaire itself. These instructions describe the kinds of questions the respondents will answer, what they are supposed to do with the questionnaire when they finish it, how much time they will have, etc. Transitional instructions "introduce a 
section or provide a transition between sections of a questionnaire" (p. 73), so that the respondent knows that the topic is changing, or there is a different context for questions that follow. Also, the subjects will know what to do next. Finally, question-answering instructions provide the subjects with more detailed directions for answering the questions.

\subsubsection{Format of the Questionnaire}

The physical design and layout of the instrument is an important issue for the researcher to consider. For formatting questionnaires, the following are suggested by Bourque and Fielder (1995, pp. 102-103).

Adequate spacing between questions is important to help clarify where one question stops and the next begins. Avoiding italics, which are difficult to read, may avoid alignment problems and improve the readability of the text. Using boldface fonts, underlining, and CAPITALIZATION helps to emphasize something important in the text or highlight an instruction to the subjects. However, whatever formatting is done such as single-spacing or double-spacing, underlining or bolding must be consistent throughout the questionnaire.

A common error made in questionnaires is to split a question or an instruction between pages for the sake of saving space. Mostly, respondents get frustrated and leave split questions blank due to the effect that the visual interruption occasioned by the formatting has upon their comprehension of the question or the instruction. Besides their frustration, respondents may fail to see the complete list of responses or instructions and, as a result, they may end up never reading or considering the second part on the second page, which will lower the number of people selecting those options. 
The final portion of the instrument may include a section where the subjects can reflect what they feel about the questionnaire itself. They can add further comments for future reference or make suggestions about what is missing in that particular questionnaire or even complain about it.

\subsubsection{5 $\underline{\text { Cover Letter }}$}

The use of a cover letter is suggested because it helps the respondents understand the importance of the study, the reasons why the respondents' participation is important, the realistic estimate of the time required to complete the questionnaire, the personal confidentiality of the information, and the names of contact people. To broaden the content of a cover letter in order to motivate respondents, Bourque and Fielder make the following recommendations (1995, pp. 106-107):

1. Use a letterhead.

2. Provide information about sponsorship.

3. Include a date.

4. Begin with a salutation.

5. State the purpose of the study.

6. Give reasons why an individual's participation is important.

7. Encourage respondent participation.

8. Use advance letters.

9. Explain how material incentives will be distributed.

10. Make a realistic estimate of the time required to complete the questionnaire.

11. Give reasons how and why the respondent was chosen.

12. Explain the confidentiality and data handling. 
13. Provide a name and phone number to call for information.

14. Explain when and how to return the questionnaire.

A good cover letter will increase the quality of presentation and the professional appearance of the questionnaire to stimulate respondent interest. However, the selection of the contents to be included in a cover letter depends on the surveyor's preference.

In conclusion, demographic questions, thematic focus, question and response items, instructions, formatting, and the inclusion of a cover letter are all characteristics of a good questionnaire. Applying these criteria to the preparation of the instrument increases the validity of the potential questionnaire. On the other hand, every respondent group or the administration of each questionnaire may differ in many ways which may make it necessary to reorganize these criteria. In the following section, the re-formatting of the original questionnaire as well as its effective characteristics will be discussed with reference to this model.

\subsection{The Formation of the Original Questionnaire}

\subsubsection{A Selection of a Format for Administration}

The original questionnaire was designed to function as a self-administered questionnaire given to a group in the presence of a surveyor. The singular purpose of the questionnaire was to gather information about the respondents' perceptions of three aspects of American culture: family, education, and gender roles. Unfortunately, it soon became clear to the investigator that the questionnaire did not provide the information expected. As a result, the project shifted completely away from the original purpose -collection of cultural data -- and focused on the problems inherent in the instrument. At 
that point, the researcher initiated a comprehensive re-design of the questionnaire. It is this redesign that has become the objective of the study and the topic of the thesis.

In this study, the purpose was to design a cultural needs questionnaire which was given to Intensive English Program students who had recently arrived in the U.S. This original questionnaire was designed to distinguish the students' levels of cultural awareness. Keeping this objective in mind, the researcher aimed to determine whether the cultural needs questionnaire worked or not, whether the foreign students understood the culture questions asked, and whether the response categories provided the underlying American values behind the cultural behavior patterns. Similarly, Bourque and Fielder (1995) state that, “...the surveyor will probably want to learn as much as possible about how the questionnaire 'works,' whether the respondents understand the questions asked, whether the information requested is accessible to respondents, and whether the response categories provided are exhaustive, mutually exclusive, and readily understood " (pp. 45).

Another reason for the preference of group administration for this particular study was the availability of comparing the intergroups to each other on a specific topic. In the present study, there were different cultural groups that reflected their own cultures and their understanding of the American culture. Bourque and Fielder cite a similar objective as the questionnaires are " developed to assess how a particular individual respondent compares with other groups of respondents" (p. 5). The third reason in choosing a selfadministered questionnaire over an interview was the belief that people are more likely to give their sincere opinions or feelings on sensitive topics if it is a questionnaire that they will answer by themselves. 
As a group administration, in our study, the subjects were in the same place, a classroom at West Virginia University in the Intensive English Program. Every subject heard the same verbal instructions, and as Bourque and Fielder suggest that "everyone's questions or comments are handled in a similar way" (p. 6). Besides being a group administration, the original questionnaire was also a good example of a "semisupervised" administration in which "the person who distributes and collects the questionnaires is available to answer questions or provide instructions" (p. 7). However, the explanations were limited to the clarification of instructions since any further explanations about an American concept or an American behavior in a question could manipulate or mislead the student's opinion on that particular subject.

\subsubsection{Questionnaire Construction}

In this study, only three subject areas- family, education, and gender roles- were used in order to limit the questionnaire; even though, these subject areas are not the only topics relevant to cultural needs. Bourque and Fielder also argue that a self-administrated questionnaire should be short and accordingly, the topic areas should be limited.

The questions asked in the original questionnaire were all closed-ended ones. However, the choice "other" was added in order to increase flexibility in answer categories. Adding "other" gave the subjects an opportunity to reflect their own cultural values. On the other hand, in order to keep the respondents' answers consistent, this usage was minimized by including more possible answers to each question. The only problem which occurred as a result of the effort to minimize the usage of "other" was the researcher's limited knowledge of each respondent's own culture. Generating more possible answers to each question became difficult. Bourque and Fielder's research 
support the closed-ended question usage since the majority of respondents prefers closedended questions. They state the reason as "respondents do not like to answer open-ended questions partly because the physical process of writing out an answer is tiring" (1995, p. 59). In the usage of "other," they offer two ways of handling the residual "other" answers in data analysis: either moving the volunteered answer into one of the existent variable categories or creating a new variable. In this study, the respondents' other answers were used to create new response items in the modified questionnaire.

The language was English and the respondents were non-native speakers in this study. They might have needed more detailed instructions compared to native speakers. Therefore, the transitional instructions were printed in bold and informed the subjects how to answer the questions or when to proceed to another part of the instrument, e.g., from the demographic questions to the content questions. The culture-specific terms, i.e., househusbands, commuter couples, and blended families, were also printed in bold to attract the students' attention to these terms. Bourque and Fielder also underline the importance of instructions. They believe that the instructions are particularly important where there is no administrator who can help the respondent understand the questions or explain what is to be done in the completion of the questionnaire.

In this study, one question was gender specific, i.e., - females answered the part related to females, and vice versa -, and therefore, skipping was used to facilitate the question's applicability to all potential respondents although the usage of skipping is discouraged by Bourque and Fielder. However, the skipping did not result in multiple branching, and it was explained to the subjects with a question answering instruction. 


\subsubsection{Content of the Questionnaire}

In the present study, the demographic questions were quite important since they provided information about which cultures the subjects came from and whether the male or female subjects answered the gender-specific questions. These questions are placed in the beginning of the questionnaire.

In the original questionnaire, the questions were designed to measure how the subjects feel or think about the American culture currently, i.e., not after or before their acculturation to the new culture. Bourque and Fielder (1995) explain that focusing on the present time works better (p. 26). In addition, the subjects in this study were from different language and cultural backgrounds. The level of English and the vocabulary were carefully controlled and kept simple in order to be comprehensible for each subject. Also, the questions related to the subjects' own cultures were designed not to be specific to only one culture, but to one's home culture in general. The authors emphasize the same idea by saying that the applicability of the question to each respondent is necessary to make the question amenable (p. 27).

\subsubsection{Question Items}

The question items proposed in the questionnaire were designed for only one American culture behavior and/or concept, or for one native culture behavior and/or concept. Bourque and Fielder explain that a question should not ask two things at once. This study preferred using "always," "often," "sometimes," "seldom," and "never" to measure the frequency of the respondents' behaviors. However, the writers suggest that the questionnaire designers should avoid vague qualifiers such as "usually" since the 
possibility that this response item may give the researcher imprecise information about the respondents.

The questionnaire introduced new cultural terms related to American culture to the non-native subjects. These abstract terms or jargon, i.e., "househusbands," “commuter couples," and "blended families," were introduced with their definitions in the questions to lessen the respondents' confusion. Bourque and Fielder strongly argue that "surveyors must be particularly careful to minimize the use of abstract terms or jargon ... when used, to carefully assess that respondents understand it" (p. 47). Moreover, these newly introduced American concepts in the original questionnaire were written in bold to draw the subjects' attention to them.

The suggestion of Bourque and Fielder on ordering the questions from easiest to more complex and/or sensitive ones did not exist in this study since the proposed questions were about different cultural aspects. Consequently, there was no such distinction between the questions as difficult or easy. However, some questions were on the same topic or topics closely related to each other, and on that account, such questions were grouped together, for example, questions related to classroom, education system or student-teacher relationships are categorized in one group related to education. Also, the questions on the three topics, i.e., family, education, and gender roles, are subcategorized under these main topics.

\subsubsection{Response Items}

In the present study, some of the response items were as long as the actual questions since they presented a cultural behavior that needed to be given in full description. They reflected ideas rather than a short answer. However, these questions 
did not have the possibility that "respondents fail to see the complete list and, as a result, never read or consider those responses found on the second page" (Bourque \& Fielder, 1995, p. 101). The questions allowed the respondents to see the entire list of responses on the same page or section.

\subsubsection{4 $\underline{\text { Cover Letter }}$}

As a final step in the design of the questionnaire, the cover letter was prepared. This letter mentioned that the participation of the subjects was voluntary, and if they chose not to participate, it would not affect their grades. Also, the telephone number of the Executive Secretary of the Institutional Review Board was given in the cover letter if the subjects had any questions about their rights as a participant in this research, or if they felt that they had been placed at risk.

\subsection{Modified Research Design}

The background research and the questionnaire given to students at the West Virginia University Intensive English Program in connection with the pilot study provided insights as to what modifications and/or revisions must be made to develop a more accurate survey for the intended purposes. The objective of this study was to design a cultural needs questionnaire. The instrument was then administered to a sample population in order to determine areas that might need to be modified in a subsequent version. In the evaluation of the non-native students' responses to this study, the following data can be considered for a second draft of the survey. In this section, the researcher will describe the inadequacies that rendered the survey instrument ineffective and inconclusive, and discuss a number of modifications and revisions that might improve the questionnaire. 


\subsection{1 $\underline{\text { Problems }}$}

\subsubsection{Problem I: Establishment of a Base-line or Control Group}

The first problem was the failure to include responses to the questionnaire by a control group. Before administering the questionnaire, the researcher should have established a clearly defined control group from whom to gather and analyze data related to the target culture. This method would allow the researcher to establish a base line of responses from representatives of the host culture against which to compare the responses of the sample.

\subsubsection{Problem II: Selection of a Sample Population}

The questionnaire under development was intended in part to determine the level of cultural awareness and the amount of exposure the newcomer receives, such as living with or without a direct cultural involvement in organizations or activities pertinent to the host culture. However, the original instrument did not attain this objective since there were too many intervening variables (e.g., length of stay, age, participation in American organizations, enjoyment of American Culture classes, various academic levels, unequal gender and cultural distribution, or occurrence of any cultural misunderstandings) that may have affected the results. With so many factors to be considered beyond the target focus, it was impossible to determine the relationship between cultural exposure and knowledge and the possible cultural awareness of different ethnic groups of the new culture based on the data collected.

A second problem in the pilot study related to the sample was the inadequate number of subjects. To eliminate this problem, the researcher should obtain a larger sample from the targeted population in any subsequent study. Having only 19 students 
spread across five cultural groups invalidated the research. This larger sample would then represent a more limited number of different cultures and an equal number of men and women to control for gender bias within different cultural groups. In addition to the question of sample size, a more adequate sample group would reflect the following characteristics:

1. The subjects would be selected from students only between the ages of 18-25. This criterion would control for a possible age variable in the data, which the present study did not do.

2. Only the students who had been in the U.S.A. less than one year would be chosen to participate, which would control for the effects of assimilation after arrival as much as possible.

3. There would be only students of language programs associated with postsecondary institutions who mostly come to these programs to learn English in order to further their education.

4. The researcher would extend the survey to include more than one English language program in the region, which would increase the survey population, and, thus provide more responses from which to then choose the subjects that met the selection criteria. Further, keeping the survey as regional/statewide as possible would control for variations in regional characteristics of the host culture.

5. Only undergraduate students would be included in the study to control for the possibility that undergraduate and graduate students may respond to the cultural concepts or behaviors differently. 
6. In addition, there would be a control group of American students age 18-25 attending college in the region and native to the area who would respond to the survey. The investigator would then be able to compare the data obtained from the experimental groups, which the present study did not have. This survey would be given to a minimum of 30 American students only from the region.

\subsubsection{Problem III: Design of Questionnaire}

In addition to making changes in the experimental and control group selection, the questionnaire itself should be modified. The first problem noted was the excessive number of questions. Therefore, the length of the questionnaire has been reduced from 39 to 31 items. The second problem that the questionnaire had was the number of choices in each question. Again, the number of choices in the modified questionnaire has been reduced to provide a more consistent focus. Also, the choice of "other" was deleted in the questions since that response item did not enhance the data. The following modified questionnaire reflects the changes incorporated as a result of the pilot administration. Some questions from the original have been deleted, others have been added, and some are rephrased. The reasons for the changes, additions, and deletions are discussed following each question.

\subsection{Modified Questionnaire}

\section{Circle the one (1) answer that describes you the best. Fill in the blank in necessary}

\section{items.}

The instructions were given orally in the original administration. However, a written instruction would be more helpful to non-native respondents. 


\section{Background Information}

1. Your Country:
2. Age:
a. $18-25$
b. $26-35$
d. $36-45$
e. $46-55$

3. Gender:
a. male
b. female

4. Name and location of the language school you are attending :

This question is added to control for regional differences, cultural attitudes and beliefs that might affect responses. The responses will enable the researcher to choose the students who go to language institutions or language schools only in West Virginia.

5. Educational Background (circle the highest level completed) :
a. elementary school
c. undergraduate
b. high school
d. graduate

"Circle the highest level completed" is added as a further explanation since lack of this explanation caused some students to misunderstand and choose the level they are currently attending. The choice "university" is replaced by "undergraduate" and "graduate" in order to refine the responses received.

6. How long have you been in the U.S.?
a. less than one year
c. three-four years
b. one-two years
d. more than four years

No change has been made to this question.

7. Do you live with an American roommate or an American family?
a. yes
b. no

8. How often do you join or participate in American organizations, social clubs or events? 

a. always
b. often
c. seldom
d. never

The choice "sometimes" is omitted in order to get a clearer indication of the students' participation. "Often" and "seldom" are substituted for "sometimes" since these two choices show frequency from both negative and positive perspectives whereas "sometimes" does not give such information.

Questions 8 through 10 in the original questionnaire have been deleted, since the researcher found that the results did not contribute significantly to the research question under investigation.

Questions 11 and 12 from the original questionnaire have been deleted, since they were difficult for the students to understand and contributed no significant data to the investigation.

\section{Content Questions}

\section{Choose the one ( 1 ) answer that best represents your idea.}

9. At what age do young people move out of their parents' house in your culture?
a. $16-20$
b. 20-above
c. when they get married

d. when they get a job

e. none of the above

Instead of using the phrase "become independent," "move out" is preferred because the concept of "becoming independent" can be interpreted differently by members of different cultures. The focus of this item was to determine if and when young people move out of the parents' house in the students' home cultures. The choice "none of the above" is added since in some cultures, young people may not leave their parents' houses. 
10. In the U.S.A, many teens who reach the age of 18 leave their parents' house to live by themselves. You think

a. American parents do not care enough about their children.

b. American young people do not like their parents.

c. American young people want to live independently.

d. American young people do not want to be a burden to their families anymore.

The choice "c" - not being educated enough - and the choice "d" - not being mature enough- from the original questionnaire have been deleted, since there were too many negative explanations as response items, and because they do not reflect the reasons why students move out of their parents' houses.

11. In the U.S.A., many older people reside in a nursing home or retirement home rather than live with their children. In your opinion, it is
a. unacceptable
b. acceptable
c. not desirable, but necessary

In the stem of the item, the word "prefer" is replaced with "reside," since living in a nursing home or retirement home may not be a preference. The choices are reduced to "unacceptable" and "acceptable." The choice "not desirable, but necessary" is added as a result of further consideration, and in order to provide a response that might more accurately reflect the attitude of the host culture.

12. Who lives together as a family in your culture?
a. only parents and children
b. parents, children, and grandparents
c. parents, children, grandparents, and other relatives
No change has been made to this question. 
13. Who makes decisions for a family in your culture?
a. father
b. mother
c. mother and father
d. other relatives

The original item, which read "In the U.S.A., families no longer believe that 'Father's word is law'" is deleted, since this question focuses on the students' own culture, not on American culture. The choices "grandfather," "uncles," and "aunts" would now be included under the choice "other relatives." By the same token, "mother and father" can represent "the whole family."

14. The U.S.A. has one of the highest divorce rates in the world, perhaps even the highest. In your opinion, why do so many Americans get divorced?
a. loose family ties
d. financial problems
b. alcoholism
e. marital infidelity
c. domestic violence
f. marriage at a young age

The choice "unemployment" has been deleted because it is a subdivision of "financial problems." "Effects of feminism" and "effects of male chauvinism" are deleted since they were new terms for some of the students surveyed. Students did not have a clear understanding of the terms. The choice "marriage at a young age" has been added as a result of further consideration, and in view of the fact that there are differing perceptions of what constitutes "a young age."

15. How easy/difficult is it for couples to get divorced in your culture?
a. easy
b. difficult
c. not possible

This question was added to the questionnaire because the researcher made an overgeneralization by assuming that in every culture people accept the concept of 
divorce. However, the pilot study showed that some cultures do not have divorce. This question will help the researcher to see which cultures allow it and which do not.

16. If it is possible to get a divorce in your culture, under what circumstances would couples get divorced in your culture?
a. loose family ties
e. marital infidelity
b. alcoholism
f. marriage at a young age
c. domestic violence
g. not applicable
d. financial problems

The phrase "if it is possible to get a divorce in your culture" has been added to the main question assuming that some cultures do not have divorce. Due to this change, the students will have the option of choosing "not applicable" if they do not have divorce in their cultures. The choice "unemployment" is deleted again because it is a subdivision of "financial problems." "Effects of feminism" and "effects of male chauvinism" are deleted for the same reasons discussed in reference to question 15.

17. Some American concepts are listed below. Whether or not you have these concepts in your culture, choose the answer that best describes your opinion.

A. Househusbands (the woman's work supports the family, and the man takes the responsibility for the house and the children)

I think that
a. American men are weak.
b. it is o.k. Why not? As long as she makes money, who cares?
c. American women are insistent upon equal treatment.
d. each individual should do what he or she does best. 
e. it is not right since a man cannot completely function as a mother.

f. it is necessary because economic conditions push them into this situation. In choice "c," the term "feminist" is changed to "insistent upon equal treatment" to soften the response and to avoid misunderstanding of the term.

B. Commuter couples (the wife and husband work and live in different geographical locations and see each other on weekends or less often)

I think that

a. everything is money for Americans.

b. the lack of employment opportunities in the U.S. forces couples to live separately.

c. the relationship between a wife and husband in this country is loose.

d. it is sometimes necessary to live apart since living expenses are very high in the U.S.A.

e. the American family system has already dissolved.

The choice "American women have no respect for the family institution" is deleted since this option was too gender-biased.

C. Blended families (families composed of previously-married adults and the children of their previous marriages)

I think that

a. blended families are the reason many American teens have problems.

b. blended families help to create a more secure home environment for children.

c. the marriage institution in the U.S.A. is corrupted.

d. the marriage institution in the U.S.A. is strong so divorced adults want to remarry. 
The choice "every marriage has ups and downs, so I would wait until we solved our problems" and "I would get divorced and remarry for my well-being and the wellbeing of my children" in the original questionnaire are deleted. The first one was similar to the current choice "b" and the latter choice was similar to the current choice "d."

18. In the U.S.A., teenagers earn their own spending money by delivering newspapers, cooking or washing dishes in a restaurant, or mowing lawns. For some families, delivering newspapers is a common job for a 12-year-old. In your opinion, a. teenagers learn the value of money by working.

b. families are too materialistic.

c. teenagers are getting used to taking responsibility.

d. parents should provide everything for the family.

In the question part, the phrase of "to deliver newspapers is conceived of as 'good training' for a 12-year-old" is deleted and rephrased in the question because this wording gives the explanation of the underlying reason in the question which can be a clue for the students. Among the choices in the original questionnaire, "poor children learn about life at an early age" is deleted because the word "poor" is ambiguous. The researcher used the adjective "poor" to indicate " they are too young to work" whereas the students thought that the children were "financially" poor. Also, in the same choice, the phrase "children" was conflicting with the question itself in which "'teens" was used. The choice "what happened to the concept of 'Father is the breadwinner' and the last choice "teenagers should study for their classes instead of delivering newspapers" in the original questionnaire are deleted, and a new choice "parents should provide everything for the family" is introduced as a new option. 
19. In your culture, when a young girl reaches the marriage age, what happens?
a. she marries the one she chooses.
b. she can choose her spouse, but her father must approve of her choice.
c. both parents (if living) must approve of her choice.
d. her relatives arrange the marriage for her.

The choice "she can choose, but her father must approve of her choice" is added according to the students' further suggestions, which enabled the researcher to improve this option as stated. "She finds a partner in the newspaper advertisements" is deleted since it is not very common in real life for most cultures. The phrase "match-make" is replaced by "arrange the marriage" because the researcher realized that there is no such verb in English. "Both parents (if living) must approve of her choice" is also added since assuming that the father is the dominant figure in every culture would be wrong. This choice allows for cultures in which both parents make a decision together.

20. In America, before getting married, the bride and the groom may give a list of possible wedding gifts to a store. The guests go to this store and choose one of the items as a gift for the couple. You think it is
a. greedy
b. rude
c. direct
d. considerate

The choices "useful" and "logical" are deleted. The underlying American value in this custom is "directness;" therefore, the choice "direct" is added in order to replace the deleted ones. The choice "considerate" is also added since it provides another viable option.

21. A. (This question will be answered by only female students) Mark the main characteristics of a traditional husband in your culture. 
A traditional husband in my culture

a. decides about family matters with his wife.

b. makes his wife do everything such as taking care of the children, their school work, and the house.

c. shares the household work with his wife equally.

d. controls the family so everything is peaceful, but everyone is unhappy.

The choices "dominates the family so everything is peaceful and organized" and "dominates the family so everyone is controlled, but unhappy" from the original questionnaire are combined and reformed as a new choice "controls the family so everything is peaceful, but everyone is unhappy." Also, in choice "b," the term "the bills" is deleted from the option as it confused the students as to whether the housewife works and pays the bills or just organizes them.

B. (This question will be answered by only male students)

Mark the main characteristics of a traditional wife in your culture.

A traditional wife in my culture

a. obeys her husband.

b. pretends to obey her husband in public, but has equal control in the family.

c. works and supports the family as does her husband.

d. does not have a job and fulfills her household duties.

The original choice "e"-dominates the family, so everything will be under controlis deleted because of its similarity to the choice " $b$ "- pretends to obey her husband in public, but has equal control in the family- in the original questionnaire. The original choice "d" was "does not work..." It was modified to "does not have a job..." since 
doing housework is seen as working. The intended purpose of the question was that the wife does not have a job outside of the home which pays a regular salary.

Question 26 - meeting a young woman - is deleted. The researcher realized that this question is gender-biased, and it is not fair to ask this question to female students expecting them to think as the males would think.

22. You have gone out with someone four or five times and you like this person very much. What level of touching is acceptable in public?
a. holding hands.
b. the man or woman may put his/her arm around his/her partner's shoulder or waist.
c. kissing.
d. no touching at all.

The choices "a"-kissing hello and good-bye on the lips- and "d"- passionate kissing- in the original questionnaire are similar; therefore, they are combined and rephrased as a new choice "c"- kissing. - According to the students' suggestions, a new choice of "no touching at all" is added.

23. It is assumed by foreign students that getting into an American college and studying in the U.S.A is quite easy. You think
a. it is true
c. it is the same as a college in your country
b. it is harder than in your country
No change has been made to this question.

24 . What is the role of the teacher in your country?
a. a tyrant
b. a facilitator
c. a friend
d. an information authority 
The choices "d" - a mentor- and "e" - an information source - from the original questionnaire are deleted, and rephrased as "d" - an information authority - in the revised questionnaire.

25. In the U.S.A., the students are encouraged to criticize or even contradict their teachers. You think it is accepted because

a. most professors do not do their job efficiently.

b. students learn by questioning beliefs.

c. professors know that discussion leads to new ideas.

d. students have no respect for their professors.

The choices "e" - students show their interest in the class - and "f" - students are responsible for their own learning - from the original questionnaire are deleted since the first choice is similar to the current choice " $b$ " and the latter one is similar to the current choice "c."

26. In the U.S.A., students sometimes call their professors by their first names, or they may have coffee with their professor after class. You think it is
a. disrespectful
b. neutral
c. friendly

In the question part, the phrase of "having beer with their professor at a bar" is replaced by "have coffee with their professor after class." It is possible that some students may be misled by the word "beer" in the question since drinking alcoholic beverages is not allowed in some religions. Additionally, the choice "b" - mutually respectful - from the original questionnaire is deleted because it was similar to the choice "friendly." 
27. Professors in the U.S.A. may establish social relationships with students outside of the classroom such as going out for coffee with them. This means that
a. you do not have to study very hard for his or her exams.
b. you can ask him or her to do a given assignment for you.
c. you still need to fulfill your student responsibilities.
d. you can go and sit in his or her office anytime you want.

The choice "b" - you can ask for his or her help about a given assignment - from the original questionnaire was misunderstood by some students; they thought that they would go and ask the questions they could not understand. However, the intended behavior meant was asking him or her to do a given assignment for the student. Therefore, the choice is rephrased as "you can ask him or her to do a given assignment for you."

28. You have failed an exam, and your professor wants to talk to you in his office about your poor grade. When he speaks to you, what do you do?
a. look in his eyes.
b. look down at the floor.
c. focus your eyes on a distant object.

The choice "c" - look up at the ceiling - from the original questionnaire is deleted due to its similarity to the choice "d" - look down at the floor. -

29. Your science professor has been explaining a problem in class. You understand the first half of the problem, but you do not understand the rest of the problem. What would you do? 
a. raise your hand and tell the professor that you don't understand. Ask him or her to explain the problem again.

b. do not ask anyone because this is very embarrassing.

c. after class, ask a friend to explain the problem to you.

d. wait until after class and speak to the professor.

No change has been made to this question.

30. While you are taking an examination, you see your classmate leaning over to copy your answers. What would you do?

a. move your paper closer so that your friend can see.

b. cover your paper so he or she can't see it.

c. tell him or her in a loud voice to stop cheating.

d. do nothing.

The choice "c" - tell your professor immediately - from the original questionnaire is deleted due to its similarity to "d" in the original questionnaire. In addition, none of the students in the pilot study chose this choice as an answer. Instead, the choice "do nothing" is added according to the students' suggestions put in choice of "other."

31. You are in art class and the teacher asks for a definition of post-modernism. You know the answer. What would you do?

a. raise your hand and wait to be called on.

b. wait for the eldest and most respected member of the class to answer.

c. do not answer the question because that would be showing off.

d. call out the answer without waiting.

No change has been made to this question. 
Question 30 - misbehaving at school - is deleted since the researcher realized that the result will not make any contribution to the research. Also, she realized that every school may have its own unique regulations and punishment system. In addition, the nature of the misbehavior or mistake was not mentioned in the question which made the students' answers invalid.

Question 31 - pressure at American college - is deleted because the researcher realized that the answers may depend on the students' personalities more than cultural traits. For example, presentations may put pressure on a student who has stage fright while teacher-student relations may put another kind of pressure on a different student who has a social hierarchy in his own school system.

The original questionnaire was designed as a needs-analysis tool to show cultural perspectives on the topics of family, gender roles, and education. However, the study did not show any significant findings due to the problems discussed above, which would indicate that major flaws existed in the design of the instrument. The pilot study helped the researcher clarify the problems and gave an opportunity to modify it for future use. In conclusion, the designing of this questionnaire was a good start in the development of a cultural needs analysis tool which hopefully will be useful to collect data that can inform teachers as they strive to combine culture and language in ESL.

The students' responses, their comments other than the proposed choices, and their questions during the questionnaire helped the researcher determine the possible modifications for the revised questionnaire. The following section will discuss the future development that would make the questionnaire more effective. 
In addition to the proposed revisions discussed above, one further modification is possible. The questionnaire can be modified to include matched questions. The questions would be designed to match between the native culture and American culture. For example, question 33 -- criticizing or contradicting teachers -- gives us an idea about what the students think about this behavior. In this particular question, 77\% of the Spanish students found this behavior positive. However, since there was not a matching question asking if they also criticize their teachers in their native culture, it is not possible to evaluate their responses from the perspective of awareness of American culture.

Another reason to use matched questions would be to determine the validity of the students' responses. One example is observed in question 15 -- older people living in a nursing home -- and question 16 -- who lives together as a family. Some students found older people living in nursing homes unacceptable. However, they also responded that only a mother, a father, and children live together as a family, which creates a contradiction between the two responses. This contradiction also weakens the validity of the students' responses. However, this kind of matched question offers a way to measure the validity of the responses.

A final issue involves Americans' responses to the questionnaire. As noted previously, this study did not use an American control group and predicted American responses based solely on library research concerning values underlying American culture. With a control group, the validity of the American culture questions can be determined.

All of these modifications would improve the questionnaire and help teachers determine the students' cultural needs better. In general, this revised questionnaire 
represents an initial step in the development of a cultural needs analysis tool. With inclusion of a control group, the questionnaire can be further developed to better meet the needs of different English teaching situations. 


\section{CHAPTER SIX}

\section{CONCLUSION}

Although the connection between culture and language has been studied over the past forty years, there was still a need for an instrument to measure second language learners' cultural awareness. Such an instrument could serve various purposes, including providing a profile of learners' cultural knowledge as well as providing information for cultural curriculum development for ESL students. To answer this need, in this study a preliminary cultural needs questionnaire was developed.

The basis for this study is the relationship between culture and language. Culture and language, either in a native language or in a second language, are inseparable. This inseparable culture and language relationship is highlighted in Schumann's Acculturation model in which acculturation is seen as "a process in which changes in the language, culture, and system of values of a group happen through interaction with another group with a different language, culture, and system of values" (Richards, et al., 1993, p. 3). When language learners are introduced to a new language and culture, they may form either negative or positive attitudes toward the new culture. Schumann (1978b) has proposed that the degree to which language learners acculturate in the new culture affects the level of their language acquisition.

Numerous factors contribute to an individual's level of acculturation. The lack of a mutual understanding between a host culture member and a native culture member may result in a cultural misunderstanding which is one of the underlying reasons for culture shock in newcomers. According to Schumann's theory (1978a), culture shock and other social and psychological variables, which determine the degree of students' acculturation, 
either promote or inhibit their language learning. Although Schumann's theory was based on a study of immigrant language acquisition, many of these same factors may affect the language acquisition of international students in a new cultural and linguistic environment.

One way to facilitate greater cultural awareness in this student population would be to incorporate specific culture teaching into the language classroom. If language teachers have a greater understanding of their students' cultural awareness or lack of awareness, they can more effectively help them to understand the new culture. To get a profile of what the students know and what they do not know about the new culture, a cultural needs questionnaire was designed and suggested in this study to help teachers identify foreign students' potential problems in a new environment.

In this proposed questionnaire, three domains of American culture; family, gender roles, and education, were explored from the perspective of a subset of American values, i.e., individualism, equality, materialism, competition, informality, and directness and assertiveness. The American values discussed and used in this study are repeatedly highlighted in American culture books which are particularly designed for language students.

Following the examination of the American values as manifested in these three domains, a preliminary questionnaire was formulated. The questions were grouped into three types: demographic, native culture, and American culture questions. Each question reflected an American behavior, attitude, or value in order to determine how the students interpreted them. To pilot the questionnaire, it was given to 19 non-native ESL students in the Intensive English Program at WVU. The statistical analyses run after the 
administration demonstrated no significant findings. The re-examination of the questionnaire revealed that there were some problems in the development of the instrument. At this point, the focus of the study shifted to the problems inherent in the questionnaire. The problems revolved around two issues: the characteristics of the sample group and the design of the questionnaire. Taking into consideration, these problems as well as the students' feedback and their item responses, the questionnaire was then revised.

Finally, the possible implementation of the modified questionnaire will be discussed. In addition to its function as a needs analysis tool, the resulting questionnaire can be used as a teaching tool in the classroom to guide discussion of students' perspectives on American culture. For instance, when it is the time to discuss one of the questionnaire topics, the teacher can go back to the questionnaire for guidance in planning the content and extent of the lessons. Students' responses can also give an indication of the students' possible misinterpretations and resulting discomfort with American culture. The teacher can prepare a culture assimilator activity, -- i.e., an activity which provides episodes of target cultural behavior that "describe a critical incident of cross-cultural interaction" -- based on a puzzling or conflict-producing situation that they misinterpreted in the questionnaire (Seelye, 1993, p. 163). The teacher and students can then discuss the American values underlying that misinterpreted behavior in class. 
In conclusion, this modified questionnaire represents a preliminary stage in the development of a cultural needs analysis tool. With additional topics, the questionnaire can be further developed to better meet the needs of different English teaching situations. 


\section{References}

Allen, E. D., \& Valette, R. M. (1994). Classroom techniques: Foreign language and English as a second language. IL: Waveland Press, Inc.

Althen, G. (1988). American ways: A guide for foreigners in the United States. Yarmouth, ME: Intercultural Press, Inc.

Barnlund, D. C. (1985). Communication in a global village. In L. A. Samovar \& R. E. Porter (Eds.), Intercultural communication (pp. 5-14). Belmont, CA: Wadsworth Publishing Co.

Bourque, L. B. \& Fielder, E. P. (1995). How to conduct self-administered and mail surveys. Thousands Oaks, CA: Sage Publications, Inc.

Brown, H. D. (1987). Principles of language learning and teaching. Englewood Cliffs, NJ: Prentice-Hall Regents.

Butler, C. (1985). Statistics in linguistics. Oxford: Basil Blackwell.

Condon, E. C. (1973). Teaching the cultural context of ESL classes. The Annual Convention of Teachers of English to Speakers of Other Languages ( $7^{\text {th }}$, San Juan, P. R., May 11, 1973).

Datesman, M. K., Crandall J., \& Kearny, E. N. (1997). The American ways. Upper Saddle River, NJ: Prentice-Hall Regents.

Díaz-Rico, L. T., \& Weed, K. Z. (1995). The crosscultural, language, and academic development handbook: A complete K-12 Reference guide. Needham Heights, MA: Allyn and Bacon.

Dodd, C. H. (1977). Perspectives on cross-cultural communication. Dubuque: Kendall \& Hunt Publishing Company. 
Genzel, R. B., \& Cummings, M. G. (1986). Culturally speaking. New York, NY: Harper \& Row.

Goodenough, W. H. (1957). Cultural anthropology and linguistics. In P. L. Garvin (Ed.), Report of the seventh round table meeting on linguistics and language study. Washington, DC: Georgetown University Press.

Hall, E. T. (1973). The silent language. Garden City, NY: Anchor press/Doubleday Books.

Hanvey, R. G. (1979). Cross-cultural awareness. In E. C. Smith \& L. F. Luce (Eds.), Toward internationalism (pp. 46-56). Rowley, MA: Newbury House Publishers, Inc.

Inglehart, M. R. (1989). Cognitive and affective aspects of cross-cultural understanding - A social psychological analysis. In P. Funke (Ed.), Understanding the USA (pp.27-41). Tubingen: Narr.

Jason, K., \& Posner H. (1995). Explorations in American culture. Boston, MA: Heinle \& Heinle Publishers.

Lado, R. (1963). Linguistics across cultures. Ann Arbor, MI: The University of Michigan Press.

Larsen-Freeman, D., \& Long, M. H. (1991). An introduction to second language acquisition research. London, England: Longman Group UK Limited.

Levine, R. L., \& Adelman, M. B. (1993). Beyond language: Cross-cultural communication. Englewood Cliffs, NJ: Prentice-Hall Regents.

Maslow, A. H. (1970). Motivation and personality. New York, NY: Harper \& Row, Publishers. 
Mabbott, A. (1994). The Acculturation Model: The theory and its implications for classroom language acquisition. ERIC ED369272.

McLaughlin, B. (1991). Theories of second-language learning. London, England: Edward Arnold.

Nitsche, R., \& Green, A. (1977). Situational exercises in cross-cultural awareness. Columbus, OH: Charles E. Merrill Publishing Co.

Oberg, K. (1972). Culture shock and the problem of adjustment in new cultural environments. In E. C. Smith \& L. F. Luce (Eds.), Toward internationalism. Rowley, MA: Newbury House Publishers, Inc.

Omaggio, A. C. (1986). Teaching language in context. Boston, MA: Heinle \& Heinle Publishers, Inc.

Oxford, R. L. (1995). Patterns of cultural identity. Boston, MA: Heinle \& Heinle.

Richards, J. C., Platt, J., \& Platt, H. (1993). Dictionary of language teaching \& applied linguistics. London, England: Longman.

Scarcella, R. C., \& Oxford, R. L. (1992). The tapestry of language learning. Boston, MA: Heinle \& Heinle Publishers.

Schumann, J. H. (1978a). The pidginization process: A model for second language acquisition. Rowley, MA: Newbury House.

Schumann, J. H. (1978b). Second language acquisition: The pidginization hypothesis. In E. M. Hatch (Ed.), Second language acquisition: A book of readings (pp. 256-271). Rowley, MA: Newbury House. 
Schumann, J. H. (1978c). Social and psychological factors in second language acquisition. In J. Richards (Ed.), Understanding second and foreign language learning: Issues and approaches (pp. 163-178). Rowley, MA: Newbury House.

Seelye, H. N. (1984). Teaching culture: Strategies for intercultural communication. Lincolnwood, IL: National Textbook Company.

Seelye, H. N. (1993). Teaching culture: Strategies for intercultural communication. Lincolnwood, IL: National Textbook Company.

Senate and House of Representatives of the United States. (1964). Civil rights act of 1964. Washington, DC: U.S. Government Printing Office.

Shavelson, R. J. (1988). Statistical reasoning for the behavioral sciences (2nd ed.). Boston, MA: Allyn \& Bacon, Inc.

Stewart, E. C. (1985). American cultural patterns: A cross-cultural perspective. Yarmouth, MA: Intercultural Press, Inc.

Szalay, L., \& Fisher, G. (1979). Communication overseas. In E. C. Smith \& L. F. Luce (Eds.), Toward internationalism (pp. 57-82). Rowley, MA: Newbury House Publishers, Inc.

Wardhaugh, R. (1991). An introduction to sociolinguistics. Cambridge, MA: Basil Blackwell, Inc.

Wolff, D. (1989). Interrelations between learning a foreign language and understanding a foreign culture. In P. Funke (Ed.), Understanding the USA (220-240). Tubingen: Narr. 


\section{Appendices}

\section{Appendix A: Original Questionnaire}

The following questionnaire is designed for foreign language students who come to the U.S. for their educational purposes. The questionnaire consists of 39 questions designed on these issues: family, gender roles, and education. It is expected that the students' answers will give feedback about their cultural backgrounds, their stereotypes about American culture, and their understanding of the new culture. Each question (or group of questions) in the following questionnaire is annotated to indicate the aim of the questions.

Background Information

1. Your Country:
2. Age:
a. $18-25$
b. $26-35$
d. $36-45$
e. $46-55$
3. Gender:
a. male
b. female

4. Educational Background:
a. elementary school
b. highschool
c. university
d. other:

5. How long have you been in the U.S.?
a. less than one year
b. one-two years
c. three-four years
d. more than four years

6. Do you live with an American roommate or an American family?
a. yes
b. no
c. other:

7. How often do you join or participate in American organizations, social clubs or events?
a. always
b. often
c. sometimes
d. seldom
e. never 
8. Do you enjoy learning about American Culture by experiencing it?
a. yes
b. no
c. other:

9. Is the American Culture course useful to you in adapting to life in the U.S.?
a. yes
b. no
c. other:

10. How often do you experience cultural misunderstandings (e.g., offending someone unintentionally or doing a culturally wrong thing at a wrong time)?
a. always
b. often
c. sometimes
d. seldom
e. never

11. In your opinion, how well do you understand each of the following attitudes, principles, or concepts of American Culture?

Rate the following 0 through 5. $0=$ not understood at all $5=$ very well understood

$\begin{array}{lllllll}\text { American values } & 0 & 1 & 2 & 3 & 4 & 5 \\ \text { Politics } & 0 & 1 & 2 & 3 & 4 & 5 \\ \text { Family Life } & 0 & 1 & 2 & 3 & 4 & 5 \\ \text { Education } & 0 & 1 & 2 & 3 & 4 & 5 \\ \text { Religion } & 0 & 1 & 2 & 3 & 4 & 5 \\ \text { Male-Female Relationships } & 0 & 1 & 2 & 3 & 4 & 5 \\ \text { Personal Cleanliness } & 0 & 1 & 2 & 3 & 4 & 5 \\ \text { Behavior in Public Places } & 0 & 1 & 2 & 3 & 4 & 5 \\ \text { Business } & 0 & 1 & 2 & 3 & 4 & 5 \\ \text { Nonverbal Communication } & 0 & 1 & 2 & 3 & 4 & 5\end{array}$


12. How similar are the expectations of your own culture to those of the American Culture?

Rate the following 0 through 5. $0=$ not similar at all $5=$ almost identical

$\begin{array}{lllllll}\text { American values } & 0 & 1 & 2 & 3 & 4 & 5 \\ \text { Politics } & 0 & 1 & 2 & 3 & 4 & 5 \\ \text { Family Life } & 0 & 1 & 2 & 3 & 4 & 5 \\ \text { Education } & 0 & 1 & 2 & 3 & 4 & 5 \\ \text { Religion } & 0 & 1 & 2 & 3 & 4 & 5 \\ \text { Male-Female Relationships } & 0 & 1 & 2 & 3 & 4 & 5 \\ \text { Personal Cleanliness } & 0 & 1 & 2 & 3 & 4 & 5 \\ \text { Behavior in Public Places } & 0 & 1 & 2 & 3 & 4 & 5 \\ \text { Business } & 0 & 1 & 2 & 3 & 4 & 5 \\ \text { Nonverbal Communication } & 0 & 1 & 2 & 3 & 4 & 5\end{array}$

Choose the one ( 1 ) answer that best represents your idea. If you cannot find the closest answer to your idea, you may add your answer as a new option.

13. At what age do the teenagers become independent from their families in your culture?
a. $16-18$
c. $20-22$
e. when they get married
b. $18-20$
d. 22- above
f. when they get a job

14. In the U.S.A, most teens who reach the age of 18 leave their parents' house to live by themselves. You think
a. American parents do not care about their children enough.
b. teens do not like their parents. 
c. teens are not educated enough and what they are doing is a mistake.

d. teens are not mature enough.

e. American parents teach their children to be independent.

f. teens do not want to be a burden to their families anymore.

g. other:

15. In the U.S.A., older people prefer to live in a nursing home or retirement home rather than to live with their children. In your opinion, it is
a. unacceptable
b. unnatural
c. natural
d. common
e. other

16. Who lives together as a family in your culture?
a. only parents and children
b. parents, children, and grandparents
c. parents, children, grandparents and other relatives.

17. In the U.S.A., families no longer believe that "Father's word is law." Who makes decisions for a family in your culture?
a. father
c. grandfather
e. mother and father
g. aunts
b. mother
d. the whole family
f. uncles
i. other:

18. The U.S.A. has one of the highest divorce rates in the world, perhaps even the highest. In your opinion, why do so many Americans get divorced?
a. loose family ties
d. financial problems
g. marital infidelity
b. alcoholism
e. effects of feminism
h. effects of male chauvinism
c. domestic violence
f. unemployment
i. other:

19. Under what circumstances would couples get divorced in your culture?
a. loose family bonds
d. financial problems
g. marital infidelity 

b. alcoholism
e. effects of feminism
h. effects of male chauvinism
c. domestic violence
f. unemployment
i. other

20. Here are some American concepts. Whether or not you have these concepts in your culture, choose the best answer that describes your opinion.

A. Househusbands (the woman's work supports the family, and the man takes the responsibility for the house and the children)

I think

a. American men are weak.

b. it is o.k. Why not? As long as she makes money, who cares?

c. American women are too feminist.

d. each individual should do what he or she does best.

e. it is not right since a man cannot completely function as a mother.

f. it is necessary because economic conditions push them into this situation.

g. other:

B. Commuter couples (the wife and husband work and live in different geographical locations and see each other on weekends or less often)

I think

a. everything is money for Americans.

b. the lack of employment opportunities in the U.S. force couples to live separately.

c. the relationship between a wife and husband in this country is loose.

d. American women have no respect for the family institution

e. it is necessary since living expenses are very high in the U.S.

f. the American family system has already dissolved. 
g. other:

C. Blended families (families composed of previously-married adults and the children of their previous marriages)

I think

a. every marriage has ups and downs, so I would wait until we solved our problems.

b. blended families are the reason American teens have problems.

c. I would stick to my first marriage for the sake of my children.

d. the marriage institution in the U.S.A. is corrupted.

e. the marriage institution in the U.S. is strong so divorced adults want to remarry

f. I would get divorced and remarry for my own well-being and the well-being of my children.

g. this is the twentieth century and it is same everywhere in the world.

h. other:

21. In the U.S.A., teenagers earn their own money for their expenses by delivering newspapers, cooking or washing dishes in a fast-food restaurant, or moving lawns. For some families, getting up early on a cold Sunday morning to deliver newspapers is conceived of as 'good training' for a 12-year-old. In your opinion,

a. poor children learn about life at an early age

b. teenagers learn the value of money.

c. families are too materialistic

d. teenagers are getting used to taking responsibility.

e. what happened to the concept of "Father is the breadwinner?"

f. teenagers should study for their classes instead of delivering newspapers. 
g. other:

22. In your culture, when a young girl reaches the marriage age, what happens?
a. she marries the one she chooses
b. her father chooses someone for her
c. she finds a partner in the newspaper advertisements
d. her neighbors match-make her up with someone
e. other:

23. In America, before getting married, the bride and the groom give a list of possible wedding gifts to a store. The guests go to this store and choose one of the items as a gift for the couple. You think it is
a. greedy
c. useful
e. efficient
b. rude
d. logical
f. other:

24. What is the concept of "macho" in the U.S.?
a. being athletic
c. being rich
e. being violent
g. being domineering
b. being handsome
d. being smart
f. being controlling
h. other:

25. (This question will be answered by female students)

Mark the main characteristics of a traditional husband in your culture.

A traditional husband in my culture

a. dominates the family so everything is peaceful and organized.

b. decides about family matters with his wife.

c. makes his wife do everything such as taking care of the children, their schools, the house, and the bills.

d. shares the household work with his wife equally. 
e. dominates the family so everyone is controlled, but unhappy.

f. other:

(This question will be answered by male students)

Mark the main characteristics of a traditional wife in your culture.

A traditional wife in my culture

a. obeys her husband.

b. pretends to obey her husband in public, but has equal control in the family.

c. works and supports the family as does her husband.

d. does not work and fulfills her household duties.

e. dominates the family, so everything will be under control.

f. other:

Questions 26, 27, 35, and 36 are adapted from the ones in Genzel and Cummings' book, Culturally Speaking (1986).

26. You are a young man in a cafeteria at school. A young woman enters to the cafeteria and you would like to meet her. What should you do?
a. make noises and follow her.
b. go up to her and tell her she is beautiful.
c. go up to her and begin a conversation.
d. invite her on a date.
e. pinch her.
f. catch her eye and smile.
g. nothing.
h. other: 
27. You have gone out with someone four or five times and you like this person very much. What level of touching is acceptable in public?
a. holding hands.
b. the man or woman may put his/her arm around his/her partner's shoulder or waist.
c. kissing hello and good-bye on the lips.
d. passionate kissing.
e. none.
f. other:

28 . What is the role of the teacher in your country?
a. a tyrant
c. a friend
e. an information source
b. a facilitator
d. a mentor
f. other:

29. In the U.S.A., students sometimes call their professors by their first names, or they have a beer with their professor at a bar. You think it is
a. disrespectful
c. neutral
e. other:
b. mutually respectful
d. friendly

30. If you misbehave or make a mistake at school in your country, you will
a. be beaten with a wooden stick
d. be suspended from the school
b. be prohibited from attending fun activities
e. be forgiven
c. get a warning from your school
f. other:

31. It is assumed by foreign students that getting into an American college and studying in the U.S.A is quite easy. You think
a. it is true
c. it is the same as your college in your country
b. it is harder than in my country
d. other: 
32. What is the one thing at an American college that puts the most pressure on you?
a. grades
d. group activities
f. oral participation
b. exams
e. presentations
g. teacher-student relations
c. homework assignments
h. other:

33. In the U.S., the students are encouraged to criticize or even contradict their teachers. You think it is accepted because
a. most professors do not do their job efficiently.
b. students learn by questioning beliefs.
c. professors know that discussion leads to new ideas.
d. students have no respect for their professors.
e. students show their interest in the class.
f. students are responsible for their own learning.
g. other:

34. Professors in the U.S. may establish social relationships with students outside of the classroom such as going out for coffee with them. This means
a. you do not have to study very hard for his or her exams.
b. you can ask for his or her help about a given assignment.
c. you still need to fulfill your student responsibilities.
d. you can go and sit in his or her office anytime you want.
e. other:

35. You have failed an exam, and your professor wants to talk to you in his office about your poor grade. When he speaks to you, what do you do?

a. look directly in his eyes. 
b. look down at the floor.

c. look up at the ceiling.

d. focus your eyes on a distant object.

e. other:

36. Your science professor has been explaining a problem in class. You understand the first half of the problem, but you do not understand the rest of the problem. What should you do?

a. raise your hand and tell the professor that you don't understand. Ask him or her to explain the problem again.

b. do not ask anyone because this is very embarrassing.

c. after class, ask a friend to explain the problem to you.

d. wait until after class and speak to the professor.

e. other:

37. While you are taking an examination, you see your classmate leaning over to copy your answers. What should you do?

a. move your paper closer so that your friend can see.

b. cover your paper so he or she can't see it.

c. tell your professor immediately.

d. tell him or her in a loud voice to stop cheating.

e. other:

38. You are in art class and the teacher asks for a definition of post-modernism. You know the answer. What should you do?

a. raise your hand and wait to be called on. 
b. wait for the eldest and most respected member of the class to answer.

c. do not answer the question because that would be showing off.

d. call out the answer without waiting.

e. other:

39. Your additional comments about American Culture experience: 
Appendix B: Tables

Table B1

$\underline{\text { Nationality and Gender }}$

\begin{tabular}{|c|c|c|}
\hline Countries & Male & Female \\
\hline Belgium & 1 & 1 \\
\hline Brazil & 1 & 1 \\
\hline China & 3 & 2 \\
\hline Colombia & 1 & \\
\hline Egypt & 1 & \\
\hline Japan & 1 & 3 \\
\hline Kuwait & 1 & \\
\hline Saudi Arabia & 2 & \\
\hline Venezuela & & \\
\hline
\end{tabular}

Table B2

Age

\begin{tabular}{|r|c|c|}
\hline Age & Male & Female \\
\hline $18-25$ & 9 & 5 \\
\hline $26-35$ & 3 & 2 \\
\hline
\end{tabular}


Table B3

$\underline{\text { Educational Background }}$

\begin{tabular}{|c|c|c|c|c|}
\hline & Elementary & Highschool & University & Postgraduate \\
\hline Arabic & & & 1 & 2 \\
\hline Chinese & & 1 & 1 & \\
\hline Dutch & & 1 & 3 & \\
\hline Japanese & & & 1 & \\
\hline Portuguese & & & 5 & \\
\hline Spanish & & 2 & & \\
\hline
\end{tabular}

\section{Table B4}

Length of Stay

\begin{tabular}{|c|c|c|}
\hline & Less than one year & One-two years \\
\hline Arabic & 3 & \\
\hline Chinese & 2 & \\
\hline Dutch & 1 & 1 \\
\hline Japanese & 3 & \\
\hline Portuguese & & \\
\hline Spanish & 9 & \\
\hline
\end{tabular}


Table B5

Living With an American Roommate or Family

\begin{tabular}{|c|c|c|}
\hline & Yes & No \\
\hline Arabic & & 3 \\
\hline Chinese & & 2 \\
\hline Dutch & 1 & 3 \\
\hline Japanese & 1 & 6 \\
\hline Portuguese & 3 & \\
\hline Spanish & & \\
\hline
\end{tabular}

Table B6

$\underline{\text { Participation in American Activities }}$

\begin{tabular}{|c|c|c|c|c|c|}
\hline & Always & Often & Sometimes & Seldom & Never \\
\hline Arabic & & & 1 & & 2 \\
\hline Chinese & & 1 & & 1 & \\
\hline Dutch & & & & 1 & \\
\hline Japanese & & 1 & 1 & & 1 \\
\hline Portuguese & & & 1 & & \\
\hline Spanish & & 3 & 4 & 1 & 1 \\
\hline
\end{tabular}


Table B7

Experiencing American Culture

\begin{tabular}{|c|c|c|c|}
\hline & Yes & No & Other \\
\hline Arabic & 2 & 2 & Only main events \\
\hline Chinese & 1 & & \\
\hline Dutch & 3 & & \\
\hline Japanese & 1 & & \\
\hline Portuguese & 9 & & \\
\hline Spanish & & & \\
\hline
\end{tabular}

\section{Table B8}

$\underline{\text { Usefulness of American Culture Courses }}$

\begin{tabular}{|c|c|c|c|}
\hline & Yes & No & Other \\
\hline Arabic & 2 & 1 & \\
\hline Chinese & 2 & & \\
\hline Dutch & 1 & & \\
\hline Japanese & 3 & 1 & \\
\hline Portuguese & 2 & 2 & 2 \\
\hline Spanish & 2 & & \\
\hline
\end{tabular}


Table B9

Experiencing Cultural Misunderstandings

\begin{tabular}{|c|c|c|c|c|c|}
\hline & Always & Often & Sometimes & Seldom & Never \\
\hline Arabic & & & & 1 & 1 \\
\hline Chinese & & & & 1 & 1 \\
\hline Dutch & & & 1 & & \\
\hline Japanese & & & 1 & 2 & \\
\hline Portuguese & & & & & 1 \\
\hline Spanish & & & 4 & 3 & \\
\hline
\end{tabular}

Table B10

$\underline{\text { Understanding of American Culture Concepts }}$

$0=$ not similar at all $5=$ almost identical

\begin{tabular}{|c|c|c|c|c|c|c|}
\hline & 0 & 1 & 2 & 3 & 4 & 5 \\
\hline American values & 2 & & 5 & 8 & 4 & \\
\hline Politics & 2 & & 4 & 7 & 4 & 2 \\
\hline Family Life & & 3 & 3 & 5 & 5 & 3 \\
\hline Education & & & 2 & 8 & 4 & 5 \\
\hline Religion & 3 & 1 & 3 & 8 & 2 & 2 \\
\hline Male-female Rel. & 2 & & & 6 & 7 & 4 \\
\hline Personal Clean. & 1 & 2 & 6 & 5 & 1 & 3 \\
\hline Behavior in Pub. & 2 & 2 & 1 & 7 & 5 & 2 \\
\hline Business & 1 & 1 & 2 & 7 & 4 & 4 \\
\hline
\end{tabular}




\begin{tabular}{|l|l|l|l|l|l|l|}
\hline Nonverbal Com. & 1 & & 5 & 7 & 5 & 1 \\
\hline
\end{tabular}

Table B11

Similarity of the Expectations of Student's Own Culture to Those of the American

\section{Culture}

$0=$ not similar at all $5=$ almost identical

\begin{tabular}{|c|c|c|c|c|c|c|}
\hline & 0 & 1 & 2 & 3 & 4 & 5 \\
\hline American values & 4 & 3 & 3 & 8 & 1 & \\
\hline Politics & 2 & 1 & 3 & 8 & 3 & 2 \\
\hline Family Life & 5 & 4 & 3 & 4 & 1 & 2 \\
\hline Education & 2 & 2 & 3 & 4 & 6 & 2 \\
\hline Religion & 5 & 1 & 5 & 5 & 1 & 2 \\
\hline Male-female Rel. & 3 & 2 & 3 & 6 & 4 & 1 \\
\hline Personal Clean. & 4 & 3 & 1 & 6 & 2 & 3 \\
\hline Behavior in Pub. & 2 & & 6 & 6 & 2 & 3 \\
\hline Business & & & 2 & 6 & 9 & 2 \\
\hline Nonverbal Com. & 4 & & 4 & 8 & 2 & 1 \\
\hline
\end{tabular}


Appendix C: Revised Questionnaire

Circle the one (1) answer that describes you the best. Fill in the blank in necessary items.

\section{Background Information}

1. Your Country:

2. Age:

a. $18-25$

b. $26-35$

d. $36-45$

e. $46-55$

3. Gender:
a. male
b. female

4. Name and location of the language school you are attending :

5. Educational Background (circle the highest level completed) :
a. elementary school
c. undergraduate
b. high school
d. graduate

6. How long have you been in the U.S.?
a. less than one year
c. three-four years
b. one-two years
d. more than four years

7. Do you live with an American roommate or an American family?
a. yes
b. no

8. How often do you join or participate in American organizations, social clubs or events?
a. always
b. often
c. sometimes
d. seldom
e. never

\section{Content Questions}

Choose the one ( 1 ) answer that best represents your idea.

9. At what age do young people move out of their parents' house in your culture? 

a. $16-20$
b. 20-above
c. when they get married
d. when they get a job
e. none of the above

10. In the U.S.A, many teens who reach the age of 18 leave their parents' house to live by themselves. You think

a. American parents do not care enough about their children.

b. American young people do not like their parents.

c. American young people want to live independently.

d. American young people do not want to be a burden to their families anymore.

11. In the U.S.A., many older people reside in a nursing home or retirement home rather than live with their children. In your opinion, it is
a. unacceptable
b. acceptable
c. not desirable, but necessary

12. Who lives together as a family in your culture?
a. only parents and children
b. parents, children, and grandparents
c. parents, children, grandparents, and other relatives

13. Who makes decisions for a family in your culture?
a. father
b. mother
c. mother and father
d. other relatives

14. The U.S.A. has one of the highest divorce rates in the world, perhaps even the highest. In your opinion, why do so many Americans get divorced?
a. loose family ties
d. financial problems
b. alcoholism
e. marital infidelity
c. domestic violence
f. marriage at a young age

15. How easy/difficult is it for couples to get divorced in your culture? 

a. easy
b. difficult
c. not possible

16. If it is possible to get a divorce in your culture, under what circumstances would couples get divorced in your culture?
a. loose family ties
e. marital infidelity
b. alcoholism
f. marriage at a young age
c. domestic violence
g. not applicable
d. financial problems

17. Some American concepts are listed below. Whether or not you have these concepts in your culture, choose the answer that best describes your opinion.

A. Househusbands (the woman's work supports the family, and the man takes the responsibility for the house and the children)

I think that

a. American men are weak.

b. it is o.k. Why not? As long as she makes money, who cares?

c. American women are insistent upon equal treatment.

d. each individual should do what he or she does best.

e. it is not right since a man cannot completely function as a mother.

f. it is necessary because economic conditions push them into this situation.

B. Commuter couples (the wife and husband work and live in different geographical locations and see each other on weekends or less often)

I think that

a. everything is money for Americans.

b. the lack of employment opportunities in the U.S. forces couples to live separately. 
c. the relationship between a wife and husband in this country is loose.

d. it is sometimes necessary to live apart since living expenses are very high in the U.S.A.

e. the American family system has already dissolved.

C. Blended families (families composed of previously-married adults and the children of their previous marriages)

I think that

a. blended families are the reason many American teens have problems.

b. blended families help to create a more secure home environment for children.

c. the marriage institution in the U.S.A. is corrupted.

d. the marriage institution in the U.S.A. is strong so divorced adults want to remarry

18. In the U.S.A., teenagers earn their own spending money by delivering newspapers, cooking or washing dishes in a restaurant, or mowing lawns. For some families, delivering newspapers is a common job for a 12-year-old. In your opinion,
a. teenagers learn the value of money by working.
b. families are too materialistic.
c. teenagers are getting used to taking responsibility.
d. parents should provide everything for the family.

19. In your culture, when a young girl reaches the marriage age, what happens?
a. she marries the one she chooses.
b. she can choose her spouse, but her father must approve of her choice.
c. both parents (if living) must approve of her choice.
d. her relatives arrange the marriage for her. 
20. In America, before getting married, the bride and the groom may give a list of possible wedding gifts to a store. The guests go to this store and choose one of the items as a gift for the couple. You think it is
a. greedy
b. rude
c. direct
d. considerate

21. A. (This question will be answered by only female students)

Mark the main characteristics of a traditional husband in your culture.

A traditional husband in my culture

a. decides about family matters with his wife.

b. makes his wife do everything such as taking care of the children, their school work, and the house.

c. shares the household work with his wife equally.

d. controls the family so everything is peaceful, but everyone is unhappy.

B. (This question will be answered by only male students)

Mark the main characteristics of a traditional wife in your culture.

A traditional wife in my culture

a. obeys her husband.

b. pretends to obey her husband in public, but has equal control in the family.

c. works and supports the family as does her husband.

d. does not have a job and fulfills her household duties.

22. You have gone out with someone four or five times and you like this person very much. What level of touching is acceptable in public?

a. holding hands.

b. the man or woman may put his/her arm around his/her partner's shoulder or waist. 

c. kissing
d. no touching at all

23. It is assumed by foreign students that getting into an American college and studying in the U.S.A is quite easy. You think
a. it is true
c. it is the same as a college in your country
b. it is harder than in your country

24. What is the role of the teacher in your country?
a. a tyrant
b. a facilitator
c. a friend
d. an information authority

25. In the U.S.A., the students are encouraged to criticize or even contradict their teachers. You think it is accepted because
a. most professors do not do their job efficiently.
b. students learn by questioning beliefs.
c. professors know that discussion leads to new ideas.
d. students have no respect for their professors.

26. In the U.S.A., students sometimes call their professors by their first names, or they may have coffee with their professor after class. You think it is
a. disrespectful
b. neutral
c. friendly

27. Professors in the U.S.A. may establish social relationships with students outside of the classroom such as going out for coffee with them. This means that
a. you do not have to study very hard for his or her exams.
b. you can ask him or her to do a given assignment for you.
c. you still need to fulfill your student responsibilities. 
d. you can go and sit in his or her office anytime you want.

28. You have failed an exam, and your professor wants to talk to you in his office about your poor grade. When he speaks to you, what do you do?
a. look in his eyes.
b. look down at the floor.
c. focus your eyes on a distant object.

29. Your science professor has been explaining a problem in class. You understand the first half of the problem, but you do not understand the rest of the problem. What would you do?

a. raise your hand and tell the professor that you don't understand. Ask him or her to explain the problem again.

b. do not ask anyone because this is very embarrassing.

c. after class, ask a friend to explain the problem to you.

d. wait until after class and speak to the professor.

30. While you are taking an examination, you see your classmate leaning over to copy your answers. What would you do?
a. move your paper closer so that your friend can see.
b. cover your paper so he or she can't see it.
c. tell him or her in a loud voice to stop cheating.
d. do nothing.

31. You are in art class and the teacher asks for a definition of post-modernism. You know the answer. What would you do?

a. raise your hand and wait to be called on. 
b. wait for the eldest and most respected member of the class to answer.

c. do not answer the question because that would be showing off.

d. call out the answer without waiting.

Please comment on any other cultural issue(s) and value(s) you notice that differ between your culture and Americans which are not included in this questionnaire. 
Curriculum Vitae

Sabah Karayegen

\section{Education}

1999

M.A. in Foreign Languages, (TESOL--Teaching English to Speakers of Other Languages), West Virginia University, Morgantown, West Virginia, U.S.A.

1995

B.A., Foreign Language Education, Middle East Technical University, Ankara, Turkey.

1989-1991

Attended Hacettepe University, Ankara, Turkey.

1989

Kdz.Eregli Anatolian High School, Kdz.Eregli, Turkey.

1984

Kdz.Eregli T.E.D. Private Elementary School, Kdz.Eregli, Turkey.

\section{Professional Activities}

Summer 1999

Teaching Assistant, Intensive English Program, Department of Foreign

Languages, West Virginia University, Morgantown, West Virginia, U.S.A.

Fall 1998-Spring 1999

Instructor, British Culture Association, Kayseri, Turkey. 
Fall 1998-Spring 1999

Lecturer, English Language and Literature Department, Erciyes University, Kayseri, Turkey.

Fall 1996-Summer 1998

Teaching Assistant, Intensive English Program, Department of Foreign

Languages, West Virginia University, Morgantown, West Virginia, U.S.A.

1988-1999

Private English Tutor,

Summer 1996-Summer 1994-Summer 1993-Summer 1992

Counselor, Deer Valley YMCA Family Camp, Fort Hill, Pennsylvania.

Fall 1995

Teacher, Kdz.Eregli High School, Kdz.Eregli, Turkey.

\section{Additional Professional Activities}

Spring 1999

Director, Drama Production, English Language and Literature Department, Erciyes University, Kayseri, Turkey.

Fall 1997

Volunteer, Three Rivers TESOL Fall Conference '97, West Virginia University, Morgantown, West Virginia, U.S.A. 